\title{
On Freezing Depositor Funds at Financially Distressed Banks: An Experimental Analysis*
}

\author{
Douglas D. Davis ${ }^{\mathrm{a}}$ and Robert J. Reilly ${ }^{\mathrm{b}}$
}

\begin{abstract}
This paper reports an experiment conducted to evaluate the effects of alterations in the terms of repayments to depositors following a liquidity suspension as well as the effect of alterations in the publicity of information about withdrawal behavior on the fragility of distressed banks.

Results indicate that a "tough" renegotiation stance, e.g. of protecting depositors who maintain their money in the bank, can quite effectively promote stability. Information provided to depositors regarding past withdrawal behavior weakens the effectiveness of a tough renegotiation policy, but reduces fragility somewhat for a more lenient rescheduling condition.
\end{abstract}

Keywords: liquidity suspension, observability, bank runs, experimental economics JEL Classification: G21, C9

\footnotetext{
${ }^{a}$ Department of Economics, Virginia Commonwealth University, Richmond VA, 23284-4000. dddavis@ vcu.edu ${ }^{a}$ Department of Economics, Virginia Commonwealth University, Richmond VA, 23284-4000. rreilly@ vcu. edu

* The authors thank for their useful comments the editor Bob DeYoung and two anonymous referees. Thanks also to Oleg Korenok, Edward S. Prescott, participants in a seminar at the Virginia Commonwealth University, and conference participants at the 2013 Southern Economics Association Meetings. The usual disclaimer applies. Thanks also to Aaron Lazar for Z-Tree programming and assistance with experiment administration. Financial assistance from the National Science Foundation (SES 1426980) is gratefully acknowledged.
} 


\section{Introduction.}

Banks and other financial intermediaries engage in maturity transformation, converting short term liabilities into illiquid assets that take on an increased value at maturity. An inherent fragility accompanies the business plan of such institutions, because concerns about solvency can trigger withdrawals that force liquidations that in turn may cause insolvency. Although in the United States bank runs have long been associated primarily with the 1929-1933 financial collapse, the financial crisis of 2008, accompanied by the collapse of a number of financial institutions, including Northern Rock in the U.K. and the U.S. investment bank of Bear Sterns, along with bank runs in Spain in the summer of 2012 and Bulgaria in the summer of 2014 showed that financial fragility remains an important issue. ${ }^{1}$

Factors affecting bank stability as well as policies that may alleviate financial fragility have long been issues of central concern in financial economics. Deposit insurance, a standard feature of banking in most developed economies, represents perhaps the primary policy for mitigating financial fragility. Intuitively, if the recovery of deposits is guaranteed, solvency concerns would give depositors little reason to withdraw their funds. Moral hazard, however, makes deposit insurance an imperfect solution, because insured deposits can motivate banks to take on overly risky portfolios. Size and scope limitations of coverage also make deposit insurance an incomplete solution. Many banking systems, particularly in developing economies, either do not offer deposit insurance or are unable to credibly claim that the government can guarantee all deposits. Even where offered, deposit insurance applies only to small scale depositors. ${ }^{2}$ Larger and institutional depositors are not covered, although the behavior of such depositors much more importantly affects bank stability. Finally, as seen in the 2008 financial crisis, many non-bank institutions engage in maturity transformation via instruments such as commercial paper, money market mutual funds and auction rate securities, where short term liabilities retain a debt-like structure. $^{3}$ These instruments are uninsured and susceptible to 'run' outcomes.

Liquidity suspension is perhaps the most frequently discussed alternative. The intuition driving such a policy is also straightforward. If depositors know that a bank will freeze

\footnotetext{
${ }^{1}$ Other prominent U.S. domestic banks that also collapsed during the 2008 crisis include IndyMac and Washington Mutual. Bankia, Spain's third largest bank collapsed in the summer of 2012 Corpbank, Bulgaria's fourth larger lender collapsed in the summer of 2014

${ }^{2}$ Moreover, in a recent study of Swiss Citizens following the 2008 banking crisis, Brown et al. (2014) report that many depositors withdraw their deposits when a bank is distress even when they are fully insured.

${ }^{3}$ Prescott (2010) nicely summarizes non-bank instruments in which short term liabilities have a debt-like structure.
} 
withdrawals prior the level that undermines the bank's solvency, then absent immediate cash needs, no depositor would feel compelled to withdraw funds early. Bank regulators, however, are rarely able to simply suspend payments indefinitely in the face of higher than anticipated withdrawals. Rather, banks more generally are able to adopt only a short term deposit freeze, and that only after a solvency crisis is underway. The most typical governmental response to a bank run is a temporary suspension of liquidity, followed by a renegotiation of payment terms to remaining depositors. ${ }^{4}$

Once a run is underway, however, simply suspending further payments at the ex ante efficient level is not optimal because the fact of a run means that some patient depositors have withdrawn, implying in turn that an immediate deposit freeze will block access to funds by depositors with short term liquidity needs. At the same time, allowing additional withdrawals deteriorates the pool of remaining assets, in this way further weakening the bank and further reducing the return to remaining depositors. ${ }^{5}$ Thus, as a policy matter, when resetting payment terms, a banking authority is faced with an important decision regarding whose interests to give precedence. The authority may alternatively adopt a 'tough' posture, skewing payment conditions toward the interests of those depositors who maintain their funds in the bank, or adopt a more 'lenient' posture towards those depositors wishing to withdraw early, either due to unanticipated liquidity needs, such as medical expenses or funds to cover mortgage payments in the case of job loss, or to concerns about bank solvency. ${ }^{6}$ The interaction between renegotiation postures and financial fragility raises an interesting behavioral question: How important is it for the banking authority to at least look like it will be 'tough' in the case some re-negotiation is needed $?^{7}$

Intimately related to re-contracting postures are the (de)stabilizing effects of information regarding withdrawal activity. Available information is typically available on only a discrete

\footnotetext{
${ }^{4}$ Ennis and Keister (2009) review some recent instances of liquidity suspensions.

${ }^{5}$ Depending on the utility functions of patient and impatient depositors, Ennis and Keister (2009) show that the optimal ex post combination of a liquidity freeze and a resetting of contract terms for remaining depositors may actually increase bank fragility ex ante relative to a scheme where no re-contracting of payments is possible. ${ }^{6}$ As Ennis and Keister (2009) observe, in the 2001 Argentinean crisis the government attempted to distinguish withdrawals motivated by unanticipated liquidity needs from those stimulated by solvency concerns by having depositors petition the Courts to make early withdrawals. Such a policy is both necessarily imprecise and enormously costly to administer.

${ }^{7}$ Although a banking authority may not be able to commit to terms of contract re-negotiation, it may certainly publicly adopt ex ante a tough or lenient posture. Here we assume that such re-contracting postures are credible. We leave to future investigation the issue of credibility.
} 
basis, and banks cannot distinguish withdrawals motivated by liquidity needs from those driven by solvency concerns. Withdrawal behavior information may interact importantly with renegotiation postures. Knowledge of limited withdrawal activity, for example, may improve the stability of an otherwise lenient renegotiation posture.

Studying interactions between negotiation postures and withdrawal information in natural contexts is difficult if not impossible. The causes of financial distress are often idiosyncratic and in any case banking authorities are effectively unable to selectively vary policy responses to financial crises. For that reason we turn to laboratory methods to generate some pertinent data. Specifically, this paper uses experimental methods to study behaviorally the sensitivity of withdrawal behavior to alterations in re-contracting conditions and information environments. We examine three re-contracting conditions, a Base condition that offers no adjustment of initial terms, a 'Lenient' condition that skews the terms of payment adjustments toward impatient depositors and a 'Tough' condition that skews the terms of payment adjustments toward patient depositors. Re-contracting conditions are examined in two information regimes, a low information 'simultaneous' regime, where, all depositors 'bank' (e.g., make hold/withdrawal decisions) absent knowledge of other depositor's actions, and a higher information 'sequential' regime that subdivides withdrawal opportunities into morning and afternoon segments. In a morning segment a subset of depositors are invited to make a banking decision. In the afternoon all depositors who did not withdraw in the morning are invited to bank again in light of information regarding withdrawal levels in the morning.

By way of preview, we find that both re-contracting conditions and information regime variations prominently affect bank stability. In the simultaneous regime, the Tough recontracting condition is a highly effective tool for promoting stability. On the other hand, in the simultaneous regime the Lenient re-contracting condition does essentially nothing to improve stability relative to a Base condition where depositors almost uniformly run by withdrawing early.

In the sequential regime the Tough condition still yields fewer withdrawals than the Lenient condition, but the difference in withdrawal frequencies across re-contracting conditions falls, with fewer unforced withdrawals occurring in the Lenient condition and more such withdrawals in the Tough condition. Analysis of individual behavior in the sequential regime suggests that the assurance of receiving a relatively high payoff for withdrawing as a morning depositor 
encourages more unforced withdrawals in the Tough condition, while in the Lenient condition dividing withdrawals into morning and afternoon segments induces depositors to coordinate on a symmetric partial run equilibrium that arises with the Lenient re-contracting condition. In summary then, we find (a) that a banking authority's anticipated response to a liquidity crisis can very importantly affect a bank's stability and (b) the effects of providing information about who has previously withdrawn can interact importantly with the anticipated rearrangement of contract terms.

The remainder of this paper is organized as follows. Section 2 reviews the pertinent literature. Sections 3 and 4, respectively, develop the experimental design and procedures. Results appear in section 5, followed by some concluding comments in a short sixth section.

\section{Literature Review}

In their seminal work Diamond and Dybvig (1983) establish a structure for isolating the elements critical to financial fragility. They construct a simple three period model. In period 0 a financial institution invests a share $(1-\theta)$ of its exogenously endowed deposits in projects which yield a homogenous return $R>1$ in period 2, and holds the remaining share $\theta$ in cash to cover the withdrawals of depositors needing liquidity in period 1. Deposits come from $n$ homogenous agents, and without loss of generality we normalize each contribution to $\$ 1$. In period 0 , depositors do not know whether they are 'patient' and will find it optimal to wait for the payment associated with asset maturity, or 'impatient' and will need to withdraw their deposits early. Rather, depositors, privately learn their types in period 1. The bank cannot distinguish patient from impatient depositors. The bank, however, does know that withdrawal needs are idiosyncratic and that a fraction $\alpha<1$ of depositors are patient, while the remaining $(1-\alpha)$ of depositors are impatient and need to recover deposits early.

The bank offers a contract for early and late returns of $c_{E}$ and $c_{L}$, respectively, where $R \geq c_{L}>c_{E} \geq 1$. Finally, in period 1 banks are subject to a sequential service constraint, in that depositors seeking repayment in period 1 must be paid in the order they approach the bank, as long as the bank remains solvent and, once made the bank may not recall repayments. ${ }^{8}$ In a now-

\footnotetext{
${ }^{8}$ In period 1 depositors make decisions simultaneously, but once decisions are made they are randomly ordered to approach the bank
} 
standard variant of this model by Cooper and Ross (1998) the bank, given a liquidity shortage, can defer insolvency by liquidating investments at a rate $\tau, 0<\tau<1$ per dollar invested.

In such an environment it is easy to verify that two equilibria exist. First, there is an efficient equilibrium where all invested assets mature for a return $n(1-\theta) R$ that the bank uses to make promised payments, subject to $\alpha c_{L} \leq(1-\theta) R$ and the period 1 liquidity constraint $\theta=(1-\alpha) c_{E}$. Second, if some patient depositors, concerned that others might also withdraw early, recover their deposits in period 1 , an inefficient equilibrium arises as the bank's period 1 liquidity constraint is violated, thereby forcing it into insolvency. As potential remedies to this fragility, Diamond and Dybvig analyze deposit insurance and liquidity suspension. ${ }^{9}$

Over the last 30 years an extensive theoretical literature analyzing and developing the basic Diamond- Dybvig framework has evolved. ${ }^{10}$ In particular, banking economists have devoted considerable effort to identifying contract conditions that eliminate the degenerate 'run' outcome as a Nash equilibrium under various information conditions (see, e.g., Green and Lin 2003, Peck and Shell, 2003 and Ennis and Keister, 2011). ${ }^{11,12}$ A corresponding experimental literature on financial fragility has also developed in the last several years. See e.g., Madiés (2006), Garratt and Keister (2009), Schotter and Yorulmazer (2009), Arifovic, Jaing and Xu (2011, 2013), Klos and Stäter (2013), Trautmann and Vlahu (2013), Kiss, Rodriguez-Lara and Rosa-Garcia (2012, 2014a, 2014b), Brown et al. (2014) and Chakravarty et al. (2014). ${ }^{13}$ These studies cover a variety of issues pertaining to financial fragility, ranging from evaluating the behavioral implications of

\footnotetext{
${ }^{9}$ They also discuss liquidity provision by a central bank, but this alternative is offered to address the issue of an aggregate shock, rather than the idiosyncratic shocks that are the topic of the current review.

${ }^{10}$ Ennis and Keister (2010a) provide a nontechnical review of much of this literature.

${ }^{11}$ Green and Lin (2003) show that when depositors are aware (at least approximately) of their order in sequence and when the financial institution observes the hold/withdrawal decisions of all depositors, the inefficient equilibrium can be ruled out. Under a different information scheme Peck and Shell (2003) show that the inefficient 'run' solution cannot be ruled out - specifically in the case that depositors do not know their order in the queue of depositors and that only those depositors wishing to withdraw actually approach the bank. More recently Ennis and Keister (2011) examine a hybrid of these two models in which depositors know something about their order in sequence (as in Green and Lin), but only those depositors making withdrawals actually go to the bank (as in Peck and Shell). Ennis and Keister establish the appealing result that in such a situation the inefficient 'run' equilibrium cannot be ruled out, but the fragile outcome will necessarily involve only a partial run, with a subset of depositors approaching the bank first choosing to withdraw. Their partial run equilibrium is similar to the ' $W H$ ' equilibrium discussed below in the text for the Lenient re-contracting condition in the sequential information regime.

${ }^{12}$ Another important branch of investigation regards the time inconsistency problem alluded to in the introduction. See Ennis and Keister (2009) and Ennis and Keister (2010b).

${ }^{13}$ Dufwenberg (2013) provides an insightful review of much of the experimental literature. The work on financial fragility is developed from a large earlier literature on coordination games. See Ochs (1995) and Cooper (1999) for surveys.
} 
variants of the Diamond Dybvig model to broader issues, such as interbank contagion and strategic asset defaults. Three features of this literature are most pertinent to the present discussion. ${ }^{14}$

First, as reported e.g., by Madiés (2006) and Garrett and Keister (2009), bank runs rarely occur in strong banks, where a 'strong' bank is one with reserves sufficient to fund a high proportion of early withdrawals. We observe, however, that the business of banking induces such institutions to assume some risk of insolvency and, as shown by Arifovic et al. (2011), with sufficient fragility, coordination on the degenerate 'run' equilibrium becomes pervasive.

Second, the effects of liquidity suspension remain understudied. The only paper of which we are aware that examines the effects of liquidity suspension behaviorally is Madiés (2006). As one of several policy treatments for improving bank stability, Madiés includes a 'bank holiday' treatment. He finds that liquidity suspension has a marginal but positive ameliorative effect on stability. Madiés, however, introduces a bank holiday as a sort of cooling off period, without either an associated maturation of assets or a re-contracting of payment terms that restores solvency, and for this reason his result is more reasonably viewed as a restart effect often observed behaviorally in repeated games, than as an evaluation of the stabilizing effect of liquidity suspension analyzed in the theoretical literature.

Third, the existing literature provides no clear consensus regarding the effects of providing depositors information about withdrawal behavior. One the one hand, Kiss et al. (2012) and Schotter and Yorulmazer (2009) report that providing information about withdrawal behavior has a strong stabilizing effect. On the basis of their results, both papers recommend that banks provide increased information about withdrawal activity. On the other hand, Garratt and Keister

\footnotetext{
${ }^{14}$ The less closely related experimental studies follow four distinct tracks. In a first track, Klos and Sträter (2008) modifies the standard Diamond-Dybvig environment in a way that allows examination of the predictions of global games theory in banking by Morris and Shin (2001) and Goldstein and Pauzner (2005). Arifovic et al. (2011) pursue a second track by studying bank runs as coordination failures. Using a simultaneous variant of the Diamond-Dybvig model, these authors vary a coordination parameter that reflects the maximum number of early withdrawals for which holding still yields a higher return than withdrawing early. Arifovic and Jaing (2013) extend work in this direction by crossing their coordination parameter with a publicly observed random 'sunspot' variable that players might use as a correlating mechanism. Third, Trautman and Vlahu (2013) study fragility from the asset side of the balance sheet, examining the behavioral incentives of debtors to strategically default on loan payments. Finally, Brown et al (2014) and Chakravarty et al. (2014) study the contaminating effects of a run on one bank on the stability of another bank in a two-bank variant of the Diamond Dybvig environment.
} 
(2009) find that information about withdrawal activity increases the incidence of unforced withdrawals. $^{15}$

The designs in these three studies differ substantially. In the Spartan three-depositor design studied by Kiss et al. (2012), the switch from a simultaneous to a sequential condition eliminates the degenerate 'run' outcome as a subgame perfect equilibrium. ${ }^{16}$ Thus, in their experiment with the switch from a simultaneous to a sequential information regime, the behavioral issue largely shifts from one of coordination (in the simultaneous treatment) to convergence (in the sequential treatment). Similarly, the Schotter and Yorulmazer designs do not present depositors with the standard run/hold coordination problem, and in their set-up the provision of withdrawal information is also factor that encourages convergence rather than coordination. ${ }^{17}$ Garrett and Keister (2009) is perhaps most closely related to the current experiment in that depositors in all treatments face an issue of coordination. Nevertheless, Garrett and Keister combine the provision of sequential information with 'forced withdrawals' that create a small probability of insolvency. ${ }^{18}$ Thus, in the Garrett and Keister experiment the observation of withdrawals may

\footnotetext{
${ }^{15}$ In a different but related setup, Brown et al. (2014) report evidence suggesting that providing information about linkages between banks may foster contagion. Specifically, the information that banks are similar in structure and condition can foster contagion in one bank when the other suffers distress.

${ }^{16}$ The Kiss et al. (2012) design consists of two 'patient' human depositors and a computerized depositor who is obligated to withdraw whenever given the opportunity. A 'run' occurs, and payoffs fall for depositors when at least one of the patient depositors withdraws. In a simultaneous information treatment each depositor makes a withdrawal decision absent information regarding the decisions of the others. In this case both 'holding' deposits to maturity and early withdrawal are Nash equilibria. In the sequential treatment depositors are randomly ordered and make a withdrawal decision in light of the hold/withdrawal decisions of the depositor(s) to previously make decisions. In this case, 'holding' by the first patient player in the sequence is the only subgame perfect choice, because this action makes holding a dominant strategy for the second patient depositor. A related paper, Kiss et al. (2014a), studies a variant of their sequential treatment to explore network effects. The authors vary informational linkages between various depositors in sequence, and show that under some linkages both the 'run' and 'wait' outcomes can be equilibria. They do not, however, find that variations in linkages affect depositors' propensities to 'hold', suggesting at least indirectly that the provision of information, may mitigate the propensity of depositors to coordinate on the 'run' equilibrium.

${ }^{17}$ Schotter and Yorulmazer (2009) study factors that affect the speed and severity of bank runs in an environment where the quality of a bank's investments is uncertain, but where early withdrawal is almost always optimal. They vary information conditions by giving all depositors a series of four consecutive rounds to simultaneously withdraw their deposits. Several treatments possess multiple equilibria, but in all cases, these equilibria are adjacent (e.g., withdrawal either at the first or at the second opportunity). In the sequential treatment depositors are informed each time of the number of depositors who withdrew in the previous rounds. Results are compared to a simultaneous condition as well as to a low information sequential information condition, where depositors make four rounds of withdrawal decisions, but do not learn how many other depositors had withdrawn in previous rounds. Schotter and Yorulmazer find that information about the withdrawal decisions of other depositors (e.g., in a sequential treatment) fosters a tendency to converge on the underlying equilibrium and in this way reduces the size and speed of bank runs ${ }^{18}$ Garratt and Keister (2009) study the behavioral effects of variations in information conditions in a more standard context where the return on the bank's investments is certain. Depositors make a series of three simultaneous withdrawal decisions, with depositors being informed of the withdrawal decisions of other depositors in the
} 
indicate that the bank is inherently insolvent, as might be the case, for example, in the event of a negative aggregate shock.

The present study addresses two gaps in the existing literature. First, we study the effects of alternative re-contracting postures on bank stability. Second, we evaluate the effects of providing depositors with information about withdrawal behavior in a context where depositors face a coordination problem both with and without withdrawal information, and where early withdrawals may not suggest inherent insolvency. As will be clearer below in our discussion of the experiment design, in order to gain some insight into the (de)stabilizing consequences of our treatment conditions we study these issues in a design that exhibits some fragility in a baseline condition.

\section{Theory and Experiment Design}

Our experiment is based on a parameterized variant of the Diamond-Dybvig model. Although the environment is by necessity stylized, the coordination game aspect of the baseline design, as well as the capacity of a bank to restructure repayment conditions to favor either patient or impatient depositors illustrates options quite generally available to a banking authority. For the initial design, in period $0, n=7$ depositors each have $\$ 1$ deposited in the bank. In period 1 $\alpha=2 / 7$ of these depositors find themselves with unanticipated liquidity needs and withdraw their deposits immediately, earning a return of $c_{E}=\$ 1.15$. The remaining five depositors are 'patient' and, barring concerns about bank solvency, will maintain deposits in the bank until period 2 to earn a return of $c_{L}=\$ 1.40$. The bank keeps $\theta=3 / 7$ of deposits in reserve, and thus invests (1- $\left.\theta\right) n$ $=\$ 4$, retaining $\theta n=\$ 3$ in reserve. Investment projects mature in period 2 , earning a return $R=\$ 1.60$ for each dollar invested. Finally, in the case the bank must liquidate investments to cover early withdrawal requests, it may liquidate invested units for $\tau=.30$ per dollar invested.

The leftmost panel of Table 1 illustrates this situation for a bank absent re-contracting opportunities. After 2 withdrawals, the bank has $\$ 4.00$ invested which, if held to maturity, will yield a return of $4 \times \$ 1.60=\$ 6.40$, plus $\$ 0.70$ in reserve for a total of $\$ 7.10$ to cover promised

sequential condition, but not in the simultaneous condition. In their baseline treatments early withdrawals never occurred. With repetition, however, participants did coordinate on the degenerate 'run' equilibrium in the 'forced withdrawals' condition in which randomly selected depositors are forced to make an early withdrawal decision. The probability of insolvency in the forced withdrawal treatment was $1 / 8$. 
payments of $5 \times \$ 1.40=\$ 7.00$. However, if a third depositor makes an early withdrawal, the bank must liquidate 1.5 invested units to recover $\$ 0.45$ needed to satisfy the request (i.e, $\$ 3.00+\$ 0.45=3 \times \$ 1.15)$, leaving the bank insolvent, with only $2.5 \times \$ 1.60=\$ 4.00$ in mature investments to cover promised payments of $4 \times \$ 1.40=\$ 6.40$. Thus, after making the promised payment to the third withdrawal the bank liquidates its 2.5 remaining investment units, for $\$ 0.75$, which it distributes evenly among the four remaining depositors, which, rounded to the nearest nickel node, is $\$ 0.20$.

Table 1. $c_{L}$ and $c_{E}$ Payoffs under Three Possible Contract Re-Structuring Conditions

Withdr
0
1
2
3
4
5
6
7

\begin{tabular}{|c|c|}
\multicolumn{2}{c}{ Base } \\
\hline$c_{L}$ & $c_{E}$ \\
\hline 1.40 & n.a. \\
\hline 1.40 & 1.15 \\
\hline 1.40 & 1.15 \\
\hline 0.20 & 1.15 \\
\hline 0.20 & 0.20 \\
\hline 0.20 & 0.20 \\
\hline 0.20 & 0.20 \\
\hline--- & 0.20 \\
\hline
\end{tabular}

\begin{tabular}{|c|c|}
\multicolumn{2}{c}{ Lenient } \\
\hline$c_{L}$ & $c_{E}$ \\
\hline 1.40 & n.a. \\
\hline 1.40 & 1.15 \\
\hline 1.40 & 1.15 \\
\hline 0.80 & 0.70 \\
\hline 0.80 & 0.70 \\
\hline 0.15 & 0.15 \\
\hline 0.15 & 0.15 \\
\hline--- & 0.15 \\
\hline
\end{tabular}

\begin{tabular}{|c|c|}
\hline$c_{L}$ & $c_{E}$ \\
\hline 1.40 & n.a. \\
\hline 1.40 & 1.15 \\
\hline 1.40 & 1.15 \\
\hline 1.20 & 0.55 \\
\hline 1.20 & 0.55 \\
\hline 0.25 & 0.25 \\
\hline 0.25 & 0.25 \\
\hline--- & 0.25 \\
\hline
\end{tabular}

Key: For each treatment the $c_{L}$ entries indicate the payment to a late (non-withdrawing) depositor given the number of early withdrawals shown in the Table's leftmost column and the $c_{E}$ entries indicate the series of payments to early-withdrawing depositors, listed by withdrawal order. For example, given 4 withdrawals in the Base treatment, patient depositors earn, $c_{L}=\$ 0.20$ each, while the first, second, third and fourth depositors to withdraw early realize $c_{E}$ returns $\$ 1.15, \$ 1.15, \$ 1.15$ and $\$ 020$, respectively.

The Lenient and Tough designs shown in the center and left panels of Table 1, illustrate two possible re-contracting schemes. In each case, prior to issuing an insolvency-inducing third withdrawal, the bank authority suspends liquidity and restructures payments in a way that restores solvency in light of a third withdrawal and for a subsequent fourth withdrawal as well. After the fourth withdrawal, however, the bank becomes insolvent in each case, and remaining assets are distributed equally among remaining depositors. ${ }^{19}$

\footnotetext{
${ }^{19} \mathrm{We}$ confine attention to re-contracting schemes of a type that a banking authority might feasibly impose in light of information that the authority would reasonably have available. In particular our proposed alternatives are distinguishable from those considered in the theoretical literature in two respects. First, our contract alternatives are limited only by feasibility without attending to their potential optimality. Identification of an optimal alternative would require specification of depositor utility functions, information which is probably not reasonably available to banking authorities. Second, rather than allowing for an indefinite number of contract adjustments by the bank in response to withdrawal behavior, we allow only a single change in contract terms.
} 
In the 'Lenient' scheme, shown in the center of Table 1, the bank places relatively more weight on the interests of those depositors who are compelled/desire to withdraw early. In this case, the bank chooses to reduce the return to withdrawing depositors by only $\$ 0.45$ from $\$ 1.15$ to $\$ 0.70$, while reducing the return to non-withdrawing depositors (those who hold) by a $\$ 0.60$ reduction in payoffs from $\$ 1.40$ to $\$ 0.80$. Given this change in payoff terms, the bank need not liquidate any investment units on the third withdrawal, because the bank has $\$ 0.70$ in excess reserves after the first two withdrawals. For the fourth withdrawal, the bank must liquidate $\$ 0.70 / \$ 0.30=2.33$ investment units, leaving 1.67 units invested for a return of $\$ 2.67$ to satisfy commitments of $\$ 2.40(3 \times \$ 0.80)$ to the remaining three depositors. On the fifth withdrawal request, however, the bank becomes insolvent and liquidates the remaining 1.67 units for $\$ 0.50$ which it distributes evenly to the remaining three depositors for $\$ 0.15$ each (rounded to the nearest nickel node).

The 'Tough' scheme, shown in the right panel of the Table, places more emphasis on returns of the non-withdrawing patient depositors. In this case, after the second withdrawal the bank reduces payments to withdrawing depositors by $\$ 0.60$ from $\$ 1.15$ to $\$ 0.55$, but the bank reduces payments to depositors who hold by only $\$ 0.20$ from $\$ 1.40$ to $\$ 1.20$. With this restructuring, the bank need not liquidate any investment units on the third withdrawal, because the bank has $\$ 0.70$ in excess reserves after the first two withdrawals. For the fourth withdrawal, the bank needs $\$ 0.40$, and so must liquidate $\$ 0.40 / \$ 0.30=1.33$ investment units, leaving 2.67 units invested for a return of $\$ 4.27$ to satisfy commitments of $\$ 4.20(3 \times \$ 1.40)$ to the remaining three depositors. On the fifth withdrawal request, the bank would have to liquidate 1.6 additional units, which would render it unable to satisfy its commitments to the remaining two depositors. The bank thus liquidates the remaining 2.67 units for $\$ 0.80$ which it distributes to the remaining three depositors for $\$ 0.25$ each (rounded to the nearest nickel node).

Incentives for patient depositors to withdraw in period 1 are also affected by the underlying information environment. In the following subsections we develop equilibrium predictions for a low information simultaneous regime and a higher information sequential regime, respectively.

2.1 The Simultaneous Regime. Suppose first that depositors are unable to view the withdrawal activities of other depositors. Patient depositors, aware only of the repayment schedule, decide whether to withdraw or hold deposits invested until asset maturity. Anticipated returns are 
determined by the total number of withdrawals the depositor expects. The return to a hold decision is determined by the total number of expected withdrawals. The return to withdrawal depends on the order among withdrawing agents that the depositor approached the bank.

Table 2 illustrates expected payoffs for participants in the simultaneous withdrawal regime. Relative to Table 1, we reformat entries in Table 2 in two ways. First, as in the experiment to be described below, we present payoffs from the perspective of a patient depositor deciding whether or not to leave her funds to maturity in the bank. Thus, entries in the leftmost column reflect conjectured numbers of withdrawals by 'other' depositors (both patient and impatient), and the headings at the top of the table are for hold and withdraw decisions rather than $c_{L}$ and $c_{e}$ in Table 1. Second, a depositor who decides to withdraw does not know her position in the queue of people who withdraw. Absent any information regarding the activity of other agents we assume that every position is equally likely. Thus, entries in the Withdraw columns in Table 2 are the average of possible payments-for example, if a depositor in the Base design thinks that three other depositors will withdraw, she would be the fourth person to withdraw, and the bank would be insolvent. Her expected payoff for holding in this case is $\$ 0.20$, the value of the liquidated bank to remaining depositors. For withdrawing, her expected earnings are the average return from being the first, second, third or fourth person selected to withdraw, or $(\$ 1.15+\$ 1.15+\$ 1.15+\$ 0.20) / 4=\$ 0.91$.

The Base design has two symmetric Nash equilibria, the selection of which is contingent on conjectures about the hold and withdrawal decisions of others. If each depositor conjectures that only the two impatient depositors will withdraw, then the return from holding exceeds that from a withdrawal. On the other hand if depositors conjecture that at least one other patient depositor will withdraw, then the expected return to a withdrawal decision exceeds the expected return from holding, regardless of the number of others who hold. Thus, the bolded entry indicates the maximum number of withdrawal decisions by others that still make a hold decision optimal.

In the Tough design, shown in the rightmost panel, notice that there is again a single switch point, but in this case the maximum number of conjectured withdraw decisions that still make a hold decision optimal increases to four. This contract is Tough to a first alteration in contract terms (after the second withdrawal) in the sense that the expected payment to a patient 
player for playing hold (\$1.20) still exceeds the expected payment for a withdrawal (\$0.85 or $\$ 0.73) .^{20}$

Table 2. Simultaneous Treatment. Expected Payoffs from Hold and Withdraw Decisions, Contingent on the Expected Actions of Others

\begin{tabular}{|c|c|c|c|c|c|c|}
\hline \multicolumn{7}{|l|}{ 'Other' } \\
\hline & Hold & Withdraw & Hold & Withdraw & Hold & Withdraw \\
\hline 0 & 1.40 & 1.15 & 1.40 & 1.15 & 1.40 & 1.15 \\
\hline 1 & 1.40 & 1.15 & 1.40 & 1.15 & 1.40 & 1.15 \\
\hline 2 & 1.40 & 1.15 & 1.40 & 1.00 & 1.40 & 0.95 \\
\hline 3 & 0.20 & 0.91 & 0.80 & 0.93 & 1.20 & 0.85 \\
\hline 4 & 0.20 & 0.77 & 0.80 & 0.77 & 1.20 & 0.73 \\
\hline 5 & 0.20 & 0.68 & 0.15 & 0.67 & 0.25 & 0.65 \\
\hline 6 & 0.20 & 0.61 & 0.15 & 0.59 & 0.25 & 0.59 \\
\hline
\end{tabular}

Note: Bolded entries highlight the maximum number of expected withdrawals for which hold is still the optimizing action.

Finally in the Lenient design condition, shown in the middle panel, there are two critical withdrawal levels. Similar to the Base condition, a depositor should withdraw if she believes that one patient depositor (e.g., three 'others') will withdraw. In this sense, this treatment is fragile with respect to a first restructuring of contract terms. However, incentives to withdraw following the restructuring are not uniform. If the depositor believes that exactly two patient depositors (e.g., four 'others') will withdraw then she maximizes her expected payoff by holding, as in the Tough condition. But if she assumes that more than two patient depositors will withdraw, it is in her best interest to also withdraw. In this way, there are two symmetric Nash equilibria in each of the designs. However, the restructuring of payoffs in the Lenient design yields a third, asymmetric Nash equilibrium where two patient depositors withdraw and the remaining three patient depositors hold. In particular, under that asymmetric partial-run equilibrium, three patient depositors believe that exactly two of the five patient depositors will withdraw, and so those three hold $(\$ 0.80>\$ 0.77)$. The remaining two patient depositors believe exactly three patient depositors will hold, and so withdraw $(\$ 0.40<\$ 0.67)$, establishing the equilibrium.

\footnotetext{
${ }^{20}$ We emphasize, however, that our Tough treatment is distinct from the notion of non-fragility proposed by Ennis and Keister (2009), e.g., that the per capita liquidation value of all assets exceeds the original payment for withdrawal. In this sense, non-fragility essentially requires that the bank provides no liquidity insurance. We here define 'lenience' and 'toughness' in terms of the relative incentives to withdraw rather than face an expected restructuring of contract terms.
} 
In summary then, in the low information simultaneous choice environment both no-run and run outcomes exist as symmetric Nash equilibria in all three re-contracting conditions. The designs are distinguishable in the number of withdrawals by others that a depositor may conjecture and still find a hold decision to be optimal. In the Base design, a hold decision maximizes expected income on the conjecture that only the two impatient depositors will choose to withdraw. In the Tough design a hold maximizes expected income if no more than four depositors choose to withdraw. The Lenient design is like the Base condition in that a withdrawal maximizes a depositor's expected income on the conjecture of more than two other withdrawals. However, as in the Tough design, a hold decision is optimal if exactly four other depositors withdraw. Finally, as explained above, the Lenient design also offers the possibility of an asymmetric, partial-run equilibrium.

2.2 The Sequential Regime. To investigate the effects of providing depositors with partial information about withdrawal behavior we construct a sequential regime that divides a decision 'day' into 'morning' and 'afternoon' segments. In the morning a subset of two depositors are selected to 'bank' (make a hold/withdrawal decision). Once morning decisions are complete, the number of morning withdrawals is made public and all depositors who did not withdraw in the morning (including those depositors selected to bank in the morning who initially elected to hold) are given an opportunity to bank in the afternoon.

Critical to assessing the informational content of withdrawal decisions by morning depositors is some inference about the identity of the depositors selected to bank in the morning. Morning withdrawals by the two 'impatient' depositors, for example, would imply that no additional afternoon withdrawals need occur. On the other hand, morning withdrawals by two 'patient' depositors would imply that at least two additional withdrawals must occur in the afternoon, diminishing the value of a hold decision. We control beliefs about the identity of depositors who may bank in morning, by drawing them from one of two urns, each of which consists of three depositors and each of which is drawn with equal probability. Urn 1 contains the two impatient depositors, who must withdraw when given the chance, along with one randomly selected patient depositor. Urn 2 contains three patient depositors who need not withdraw. Depositors know only the composition of depositor types in each urn and that each urn is equally likely to be drawn. When making decisions, they do not know which urn was actually used or the type of morning depositor(s) that withdrew. 
A depositor's payoff in the sequential game depends on when she is selected to bank, the total number of other depositors to withdraw, and in the event she withdraws, the depositor's order in the queue of withdrawing agents. Calculation of the expected returns to hold or withdraw further requires assumptions about the decisions of the other players. Nevertheless, establishing that in all three contract conditions, both the no run outcome, in which no patient depositors withdraw, as well as the full run outcome, in which all patient depositors withdraw are Nash equilibria for the sequential game is straightforward. In these cases the reasoning is identical to that in the simultaneous version: If no other patient depositors withdraw, then the observation of withdrawals in the morning must mean that they were by the two impatient depositors, and for this reason would not affect a depositor's decision to hold. If all other patient depositors withdraw, then it does not matter whether patient or impatient depositors withdraw in the morning, since all depositors will also withdraw when given the chance in the afternoon.

The sequential structure of the game, however, creates two additional symmetric strategies for patient depositors: ' $H W$ ', hold in all morning banking decisions but then withdraw in the afternoon, and ' $W H$ ', withdraw if selected to bank in the morning but then hold if selected to bank in the afternoon. The $H W$ strategy can immediately be eliminated as an equilibrium, since in every contract condition, the afternoon withdrawals will force the bank to liquidate. Any patient depositor given an opportunity to bank in the morning can increase her expected earnings by deviating and withdrawing.

More interesting is the $\mathrm{WH}$ strategy, because under an appropriate re-contracting conditions (e.g., the Lenient condition), the WH strategy is a 'partial run' Nash equilibrium in which some patient depositors (e.g., those banking in the morning) withdraw while remaining depositors hold deposits until maturity in period 2. For the $W H$ to be an equilibrium, recontracting conditions must be set so that two conditions hold: (1) In the afternoon, the expected return from holding must exceed the expected return from withdrawing, and (2) In the morning, the expected return from withdrawing must exceed the expected return from holding in the morning and then either withdrawing or holding in the afternoon. We proceed by first identifying expected payoffs on the equilibrium path in each condition and then analyzing conditions (1) and (2) above. ${ }^{21}$

\footnotetext{
${ }^{21}$ Appendix A1 supplements the abbreviated development in the text with a more general analysis of conditions necessary for the $W H$ strategy to be an equilibrium.
} 
Expected Payoffs on the Equilibrium Path: In what follows let $h_{i}$ denote the return to a depositor who holds her deposit to maturity, given $i \in\{2,3, \ldots, 6\}$ withdrawals in the game. Similarly, denote $w_{j}$ as the return to a depositor at the time they make a withdrawal decisions, given $j \in\{0,1, \ldots, 6\}$ previous withdrawals. Using this notation, for a depositor selected to bank in the morning, a withdrawal will be either first or second in the queue. Thus the expected value of withdrawing in the morning is

$$
E_{M}(W)=(1 / 2) w_{0}+(1 / 2) w_{1} .
$$

As shown in row (1) of Table 3, $E_{M}(W)=\$ 1.15$ in each contract condition, since in each case $w_{0}=w_{1}=\$ 1.15$.

Table 3. Expected Payoffs and Possible Deviations from WH Strategy

\begin{tabular}{|c|c|c|c|c|}
\hline & Base & Lenient & Tough \\
\hline & & \multicolumn{3}{|c|}{ Given an opportunity to move in the Morning } \\
\hline \multirow[t]{2}{*}{ (1) } & $E_{M}(W)$ & $\$ 1.15$ & $\$ 1.15$ & $\$ 1.15$ \\
\hline & Deviation: & & & \\
\hline (2) & $E_{M, A}(H, W)$ & $\$ 0.91$ & $\$ 0.87$ & $\$ 0.78$ \\
\hline (3) & $E_{M, A}(H, H)$ & $\$ 0.50$ & $\$ 0.95$ & $\$ 1.25$ \\
\hline \multirow[b]{2}{*}{ (4) } & & \multicolumn{3}{|c|}{ Given an opportunity to move in the Afternoon only } \\
\hline & $E_{A}(H \mid \sim m)$ & $\$ 0.40$ & $\$ 0.90$ & $\$ 1.23$ \\
\hline (5) & $\begin{array}{l}\text { Deviation: } \\
E_{A}(W \mid \sim m)\end{array}$ & $\$ 0.68$ & $\$ 0.61$ & $\$ 0.50$ \\
\hline
\end{tabular}

Note: Bolded entries highlight an agent's earnings-maximizing response in the morning or afternoon, provided that all players follow a $W H$ strategy.

Under the $W H$ strategy, getting to bank in the afternoon implies that a depositor did not have the opportunity to bank in the morning. Denote this case by $\sim m$. Thus in the afternoon, the expected return from holding equals the probability-weighted sum of three possible events: $(i)$ both impatient depositors banked in the morning (so no more withdrawals will occur in the afternoon), $P[(i)]$ times $h_{2}$, (ii) one impatient and one patient depositor withdrew in the morning (so one more withdrawal will occur in the afternoon), $P[(i i)]$ times $h_{3}$, and (iii) two patient depositors withdrew in the morning (meaning that two more withdrawals will occur in the afternoon), $P[(i i i)]$ times $h_{4 .-}$ Recalling that one urn contains one patient and two impatient 
depositors and the other urn contains three patient depositors, and that each urn is equally likely to be selected, the respective probabilities are $P[(i)]=1 / 6, P[(i i)]=1 / 3$, and $P[(i i i)]=1 / 2 .^{22}$ Thus

$$
E_{A}(H \mid \sim m)=(1 / 6) h_{2}+(1 / 3) h_{3}+(1 / 2) h_{4}
$$

Values for $E_{A}(H \mid \sim m)$ under each contract condition are listed in row 4 of Table 3.

Expected Returns from Deviations. There are three potential deviations from the WH strategy to examine: a deviation in the morning only (e.g., hold in both the morning and afternoon), a deviation in both the morning and the afternoon (e. g,. hold in the morning and then withdraw in the afternoon), and a deviation in the afternoon (to withdraw) in the absence of a morning move. Denote these deviations by $[H, H],[H, W]$, and $[\sim m, W]$ respectively. Consider first the deviation $[\sim m, W] . E_{A}(W \mid \sim m)$ equals the probability-weighted sum of the events that $(i)$ both impatient depositors banked in the morning (so no other additional withdrawals will occur in the afternoon), $P[(i)]$ times $w_{3}$, (ii) one impatient and one patient depositor banked in the morning (so one other additional withdrawal will occur in the afternoon), $P[(i i)]$ times $1 / 2\left(w_{3}+\right.$ $w_{4}$ ) and (iii) both patient depositors banked in the morning (so two other additional withdrawals will occur in the afternoon), $P[(i i i)]$ times $1 / 3\left(w_{3}+w_{4}+w_{5}\right)$. As derived above for the $\sim m$ case, $P[(i)]=1 / 6, P[(i i)]=1 / 3$ and $P[(i i i)]=1 / 2$. Thus,

$$
E_{A}(\mathrm{~W} \mid \sim m)=(1 / 6) w_{3}+(1 / 3)\left(w_{3}+w_{4}\right) / 2+(1 / 2)\left(w_{3}+w_{4}+w_{5}\right) / 3 .
$$

Row 5 of Table 3 lists pertinent values for a unilateral deviation under the Base, Lenient and Tough conditions. As is clear from the Table, in the Base condition the expected return from deviating from a hold decision in the afternoon $(\$ 0.68)$ exceeds the expected return from following the hold strategy ( $\$ 0.40$ in row 4), and thus for the base condition the WH strategy may be ruled out as an equilibrium. Further, as seen in rows 4 and 5 of the rightmost two columns in Table 3, the unilateral [ $m, W]$ deviation from the $W H$ strategy is not profitable in either the Lenient or Tough designs.

Consider next the $[H, W]$ deviation, e.g., a representative depositor $i$ has an opportunity to bank in the morning, but deviates from the WH strategy by holding in the morning and then withdrawing in the afternoon. Label the expected value of this deviation, $E_{M, A}(H, W)$. For a

\footnotetext{
${ }^{22}$ To see how these probabilities are calculated, consider $P[(i)]$, e. g., probability that the two automated (impatient) depositors were selected and withdrew in the morning.. The urn containing the impatient depositors is selected with probability $1 / 2$. Then with probability $2 / 3$ one of the selected depositors is automated and with probability $1 / 2$ the remaining selected depositor is also automated. $P[(i)]=1 / 6$ is the product of these events. Probabilities $P[(i i)]$ and $P[(i i i)]$ are calculated similarly.
} 
representative depositor $i$ this equals the probability-weighted sum of the events that $(i)$ one impatient depositor banked along with depositor $i$ in the morning (so two additional withdrawals will occur in the afternoon), $P(\operatorname{Urn} 1 \mid P)$ times $(1 / 2)\left(w_{2}+w_{3}\right)$, and (ii) one other patient depositor banked along with depositor $i$ in the morning (so three more withdrawals will occur in the afternoon), $P(\operatorname{Urn} 2 \mid P)$ times $(1 / 3)\left(w_{2}+w_{3}+w_{4}\right)$. By Bayes' Rule $P(\operatorname{Urn} 1 \mid m)=1 / 4 .{ }^{23}$ Thus

$$
E_{M, A}(H, W)=(1 / 4)\left(w_{2}+w_{3}\right) / 2+(3 / 4)\left(w_{2}+w_{3}+w_{4}\right) .
$$

The expected returns to a unilateral deviation of this type under the Base, Lenient, and Tough conditions are listed in row 2 of Table 3. Comparing row 2 to row 1 , the unilateral $[H, W]$ deviation from the $\mathrm{WH}$ strategy is not profitable in any of the re-contracting conditions, as should make some intuitive sense, because any depositor given an opportunity to withdraw in the morning makes at least weakly more than she will earn by waiting and withdrawing in the afternoon.

Lastly consider the $[H, H]$ deviation. For a representative depositor $i$ the expected value of this deviation, $E_{M, A}(H, H)$, is the probability-weighted sum of the events that $(i)$ one impatient depositor banked in the morning along with depositor $i$ (so one other additional withdrawal will occur in the afternoon), $P(\operatorname{Urn} l \mid P)$ times $h_{2}$, and (ii) one other patient depositor banked in the morning along with and depositor $i$ (so two more withdrawals will occur in the afternoon), ), $P(\operatorname{Urn} 2 \mid P)$ times $h_{3}$. Again via Bayes' Rule $P($ Urn $1 \mid P)=1 / 4$. Thus

$$
E_{M, A}(H, H)=(1 / 4) h_{2}+(3 / 4) h_{3}
$$

The expected returns to a unilateral deviation of this type under the Base, Lenient and Tough conditions are listed in row 3 of Table 3. Comparing row 3 to row 1 , the unilateral $[H, H]$ deviation from the $W H$ strategy is not profitable in either the Base or Lenient designs. In the Tough condition, however, the expected return from the $[H, H]$ deviation $(\$ 1.25)$ exceeds the expected return from following the WH strategy $(\$ 1.15)$, and thus for the Tough condition the WH strategy may be ruled out as an equilibrium.

\footnotetext{
${ }^{23}$ From the perspective of a patient depositor banking in the morning, the probability that the other depositor will be impatient is simply the probability that she was drawn from Urn 1 , given that she was drawn. Denoting $P$ as a patient depositor and $U i, i=\{1,2\}$ to identify the urns, using Bayes' rule we have $p\left(U_{1} \mid P\right)=p\left(P \mid U_{1}\right) p\left(U_{1}\right) /\left[p\left(P \mid U_{1}\right) p\left(U_{1}\right)+p\left(P \mid U_{2}\right) p\left(U_{2}\right)\right]$, or in this case $p\left(U_{1} \mid P\right)=(1 / 3)(1 / 2) /[(1 / 3)(1 / 2)+(1)(1 / 2)]=1 / 4$. Also $p\left(U_{2} \mid P\right)=1-p\left(U_{1} \mid P\right)=3 / 4$.
} 
Summarizing the above analysis, the $W H$ strategy is not an equilibrium for either the Base or Tough re-contracting condition but for the Lenient condition is a symmetric (subgame perfect) equilibrium strategy which results in a 'partial run' outcome.

Thus moving from the simultaneous to sequential information condition introduces no new equilibria for the Base and Tough regimes and for that reason the theory provides no basis for expecting a difference in outcomes across information regimes. In the Lenient condition, however, the sequential regime creates a 'partial run' outcome as a third symmetric Nash equilibrium. In this equilibrium patient depositors withdraw in the morning, but hold in the afternoon. Given that equilibrium payoffs in that partial run equilibrium yield higher payoffs than in the degenerate run equilibrium, we would expect this equilibrium to have some drawing power. For that reason we would expect to observe relatively fewer unforced withdrawals in the Lenient regime conducted under the sequential information condition than would be observed in the simultaneous condition.

\section{Experimental Procedures}

The experiment consisted of a series of twelve sessions, with two sessions conducted in each of the six regime/contract combinations, as shown in Table 4. In each session a cohort of 20 participants were randomly seated at visually isolated PC terminals and handed a set of instructions. A monitor read instructions, which were projected on a screen at the front of the lab as participants followed along on copies of their own. Following the instructions, participants took a short quiz of understanding and then played a pair of practice periods. After answering any remaining questions, the session began. ${ }^{24}$

Sessions were divided into 12 periods or 'days'. In each day participants were randomly divided into four 5-depositor groups. Each group was supplemented with two automated depositors, who played withdraw whenever given the chance, making an effective group size of 7 each day. ${ }^{25}$ To discourage super-game effects, groups were randomly reshuffled after each

\footnotetext{
${ }^{24}$ Representative instructions appear in Appendix A3. A complete set of instructions may be found at www.vcu.people/ dddavis.

${ }^{25}$ We were able to automate early withdrawal decisions, rather than force human participants to make early withdrawals, because the number and action choices of 'impatient' depositors were fixed each period. In this way our procedures differ from studies such as Garrett and Keister (2009) or Trauthmann and Vlahu (2012) and more closely resemble Kiss et al. (2012, 2014a, 2014b).
} 
period. At the end of the session, participants were paid in private and dismissed one at a time. ${ }^{26}$ Participants were 240 undergraduate student volunteers enrolled in business, economics, engineering and science courses at Virginia Commonwealth University in the fall semester of 2013. No one participated in more than one session. Earnings for the approximately 60 minute sessions ranged from $\$ 8.50$ to $\$ 23.00$ and averaged about $\$ 16.25$ (inclusive of a $\$ 6$ appearance fee).

Table 4. Matrix of Treatments

\begin{tabular}{cccc} 
Regime & \multicolumn{3}{c}{ Condition } \\
\cline { 2 - 4 } SIM & Base & Lenient & Tough \\
SEQ & 2 SIM-B & 2 SIM-L & 2 SIM-T \\
& 2 SEQ-B & 2 SEQ-L & 2 SEQ-T
\end{tabular}

\section{Results.}

5.1 Overview. The unforced withdrawal frequencies shown as Figure 1 provide an overview of results. Looking first at the simultaneous regime treatments, shown in the left bars of the figure, observe that in the SIM-B treatment depositors 'ran' frequently. The unforced withdrawal rate exceeds $75 \%$ in periods $1-6$ and rises further in periods $7-12$. Notice also that the re-contracting scheme very importantly affects the incidence of withdrawals. The Lenient recontracting condition did essentially nothing to attenuate unforced withdrawals, with the withdrawal frequency for the SIM- $L$ treatment only slightly below the comparable $S I M-\mathrm{B}$ frequency in periods 1-6, and then rising above the comparable SIM-B frequency in periods 7-12. On the other hand, unforced withdrawal frequencies for the SIM-T treatment are less than $5 \%$ in periods 1-6 and fall further in with repetition in periods 7-12. The propensity for depositors to increasingly coordinate on either the 'run' or 'no run' equilibrium is consistent with the effects of repetition reported by Garrett and Keister (2009) and Trautmann and Velhu (2012).

\footnotetext{
${ }^{26}$ Our original plan was to cross the Base regime with either the Lenient or the Tough conditions, and then rotate the order of sequence. However, in some pilot sessions, we observed possible order of treatment effects. For purposes of tractability we elected to stay with a relatively short 12-period sequence length in this initial experiment. Nevertheless, as an anonymous referee observes, order of sequence effects in this context can provide important insight into the effects of past behavior on regime changes. Previous results from the coordination games literature in general (e.g., Cooper et al.,,1990, Dubois et al., 2012) as well as from the experimental literature on financial fragility (e.g., Garrett and Keister, 2009 and Trautmann and Vlahu, 2012) suggest that experience with degenerate outcomes may very importantly affect subjects' propensities to coordinate on such outcomes. In this way, experience with bank runs may significantly undermine the effectiveness of a shift to a 'Tough' re-contracting stance. Similarly, a history of coordination on the 'good' outcome may lead to persistently good outcomes even in an otherwise very fragile environment.
} 


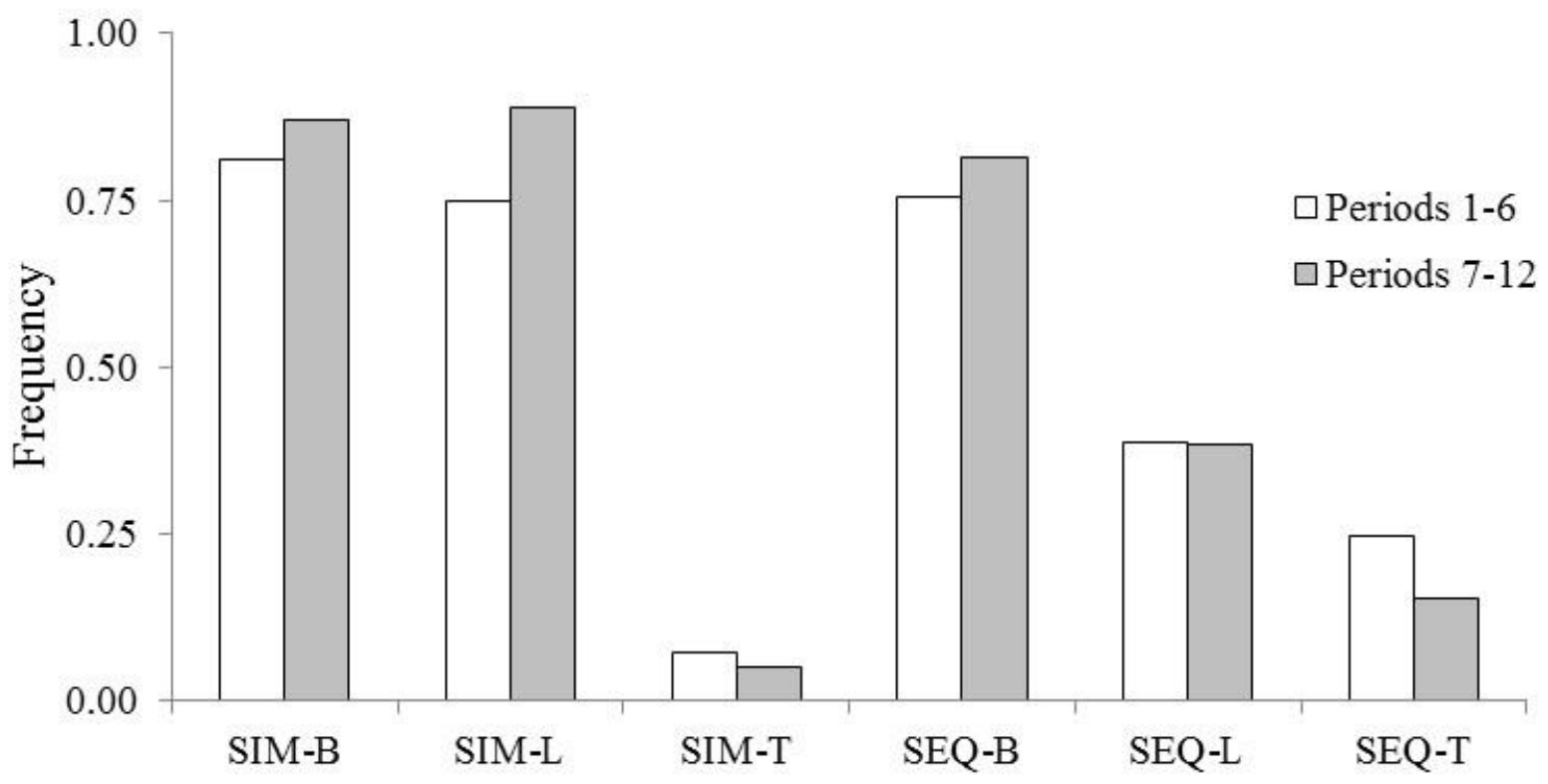

Figure 1. Unforced Withdrawal Frequencies across Treatments

In the sequential regime Base and Tough conditions again clearly separate, albeit by a rather smaller margin than in the simultaneous regime. To a large extent, an increased frequency of unforced withdrawals in the $S E Q-T$ treatment drives the reduced difference between Base and Tough treatments. In periods 1-6 the unforced withdrawal frequency for the $S E Q-T$ treatment is on the order of $25 \%$ and, while falling somewhat in periods 7-12, remains non-trivial. Notice also in the sequential regime that unforced withdrawal frequencies in the Lenient re-contracting condition fall very substantially relative to the Base condition. For both periods 1-6 and 7-12, unforced withdrawal frequencies in the $S E Q-L$ treatment are on the order of half of those in the $S E Q-B$ treatment and suggest that in the sequential information regime the 'partial run' $H W$ equilibrium outcome may have some behavioral drawing power.

Comparing across information regimes, observe first that unforced withdrawal frequencies in the $S I M-B$ and $S E Q-B$ treatments are both high and quite close in magnitude, indicating that in the Base condition depositors tend to run in either information regime. Withdrawal frequencies vary more substantially across information regimes in the Lenient and Tough re-contracting conditions, and, curiously, in opposite directions: As evidenced by the much lower withdrawal frequencies in the SEQ- $L$ treatment than in the SIM- $L$ treatment, the switch to a sequential regime substantially reduces withdrawal frequencies in the Lenient recontracting condition. On the other hand, as can be seen by comparing SEQ-T and SIM-T 
treatments, the switch to a sequential information regime raises unforced withdrawal frequencies in the Tough re-contracting condition.

\subsection{Data Analysis}

To support quantitatively the above observations we use a logistic regression to estimate individual withdrawal probabilities. Specifically, we estimate

$\ln \left[\frac{p\left(w_{i j}\right)}{1-p\left(w_{i j}\right)}\right]=\beta_{0}+\beta_{s i m-L} D_{s i m} D_{L}+\beta_{s i m-T} D_{s i m} D_{T}+\beta_{s e q-B} D_{s e q} D_{B}+\beta_{s e q-L} D_{s e q} D_{L}+\beta_{s e q-T} D_{s e q} D_{T}+u_{j}+e_{j i}$

Where $w_{i j}$ is an unforced withdrawal by participant $i$ in period $j$, and the $D_{k}$ are indicator variables that take on a value of 1 when condition $k \in\{B, L, T$, sim, seq $\}$ is true and 0 otherwise. As indicated by the structure of the error term, we control for repeated measures on individuals by modelling subjects as random effects. Finally to control for order the effects of repetition, we divide the data into halves (periods 1-6 and periods 7-12). Summary regression results appear in Table $5 .^{27}$

Consider first the estimated withdrawal frequencies for each treatment, listed aside the treatment labels in the leftmost column of the table. Starting with period 1-6 estimates for the simultaneous treatments, observe that unforced withdrawal rates for SIM-B $(0.83)$ exceed those for SIM- L (0.64) and SIM-T (0.05). As indicated by the crosses, SIM-B, SIM-L, and SIM-T estimates differ significantly from a coin toss (e.g., a 50\% probability) at $p<.01 .{ }^{28}$ Across treatment comparisons for the simultaneous information regime are shown as the top left box of the Table. Note that in periods 1-6 the estimated difference in unforced withdrawal frequencies for the SIM- L and SIM-B treatments at $-0.19(p<.01)$, while non-trivial, is dwarfed by the much larger and significant differences between the SIM-T and SIM-B treatments $(-0.78, p<.01)$ and between the SIM-T and SIM-L treatments $(-0.59, p<.01)$.

\footnotetext{
${ }^{27}$ Estimations are done with R package LME4. Complete estimation results appear as Table A2.1 in appendix A2. ${ }^{28}$ Notice that the estimated withdrawal frequencies in Table 5 differ slightly from the actual frequencies shown in Figure 1. The estimated frequencies are computed from the logit estimation procedure (e.g, $p(w \mid$ treatment $)=\frac{e^{\sum \text { treatment coeffs. }}}{1+e^{\sum \text { treatment coefs. }}}$ where $\Sigma$ treatment coeffs. is the sum of the regression coefficients needed to estimate $\ln \left(\frac{p}{1-p}\right)$ under the treatment condition. The nonlinear logit estimation procedure does not replicate observed frequencies exactly.
} 
Table 5. Tests for Treatment Effects.

\begin{tabular}{|c|c|c|c|c|c|c|c|}
\hline \multirow[b]{3}{*}{$S I M-B$} & \multirow{3}{*}{$\begin{array}{l}\text { Prob. } \\
0.83^{\dagger \dagger \dagger}\end{array}$} & \multicolumn{3}{|c|}{ Periods 1-6 } & \multirow{5}{*}{$S E Q \_B$} & \multirow{5}{*}{$S E Q \_L$} & \multirow{5}{*}{$S E Q \_T$} \\
\hline & & $S I M \_B$ & SIM_L & $S I M-T$ & & & \\
\hline & & --- & & \multirow[b]{3}{*}{---} & & & \\
\hline SIM- L & $0.64^{\dagger \dagger \dagger}$ & $-0.19^{* * *}$ & -- & & & & \\
\hline$S I M-T$ & $0.05^{\dagger \dagger \dagger}$ & $-0.78^{* * *}$ & $-0.59^{* * *}$ & & & & \\
\hline$S E Q-B$ & $0.79^{\dagger \dagger \dagger}$ & -0.04 & \multirow{3}{*}{$-0.27^{* * *}$} & \multirow[b]{3}{*}{$0.15^{* * *}$} & \multirow{3}{*}{$\begin{array}{l}--- \\
-0.42^{* * *} \\
-0.59^{* * *}\end{array}$} & \multirow{3}{*}{$-0.17^{* * *}$} & \multirow[b]{3}{*}{---} \\
\hline$S E Q-L$ & $0.37^{\dagger \dagger \dagger}$ & & & & & & \\
\hline$S E Q-T$ & $0.20^{\dagger \dagger \dagger}$ & & & & & & \\
\hline \multicolumn{8}{|c|}{ Periods 7-12 } \\
\hline & & SIM_B & SIM_L & $S I M-T$ & \multirow[t]{4}{*}{$S E Q \_B$} & \multirow[t]{4}{*}{$S E Q \_L$} & \multirow[t]{4}{*}{$S E Q \_T$} \\
\hline$S I M-B$ & $0.92^{\dagger \dagger \dagger}$ & --- & & & & & \\
\hline SIM- L & $0.86^{\dagger \dagger \dagger}$ & -0.06 & -- & & & & \\
\hline$S I M-T$ & $0.02^{\dagger \dagger \dagger}$ & $-0.90^{* * *}$ & $-0.84^{* * *}$ & --- & & & \\
\hline$S E Q-B$ & $0.87^{\dagger \dagger \dagger}$ & -0.05 & \multirow{3}{*}{$-0.51^{* * *}$} & \multirow{3}{*}{$0.07^{* * *}$} & -- & \multirow{3}{*}{$-0.26^{* * *}$} & \\
\hline$S E Q-L$ & $0.35^{\dagger \dagger}$ & & & & $-0.52^{* * *}$ & & \\
\hline$S E Q-T$ & $0.09^{\dagger \dagger \dagger}$ & & & & $-0.78^{* * *}$ & & -- \\
\hline
\end{tabular}

Key: ${ }^{*},{ }^{* *}$ and ${ }^{* * *}$ indicate rejection of the null that the difference in withdrawal probabilities under the two treatments $=0$ at $p<.10, .05$ and .01 , respectively. ${ }^{\dagger},{ }^{\dagger \dagger}$ and ${ }^{\dagger \dagger \dagger}$ indicate rejection of the null that $\mathrm{p}(\mathrm{w} \mid$ treatment $)=0.50$ at $p<.10, .05$ and .01 , respectively.

Moving to results for periods 7-12 shown in lower panel of the Table, notice that with repetition the ordering of withdrawal frequencies persists, but the difference between the Tough condition and the Base and Lenient conditions increases. Unforced withdrawal frequencies for the $S I M-B$ and $S I M-L$ treatments rise to 0.92 and 0.86 respectively, but fall to 0.02 for the $S I M-T$ treatment, with all of these estimates differing from 0.50 at $p<.01$. As a consequence, the difference between the $S I M-B$ and SIM- $L$ treatments falls to a statistically insignificant 0.06 while the difference between the SIM-T and SIM-B treatments increases to $0.90(p<0.01)$ and the difference between SIM-T and SIM-L treatments increases to $0.84(p<0.01)$. The starkly divergent effects of re-contracting conditions in the simultaneous information regime represents a first result.

Result 1: Re-contracting conditions can importantly affect fragility in a simultaneous (low) information regime. Starting from a Base environment where depositors almost always 'run', a Lenient re-contracting condition improves stability only marginally and only with limited repetition. On the other hand, a Tough re-contracting condition reduces unforced withdrawals almost to zero, and repetition amplifies these differences. 
Consider next the sequential information regime. Starting with the period 1-6 results notice again the same rank-ordering of unforced withdrawal frequencies observed in the simultaneous information regime, with $S E Q-B(0.79)$ exceeding $S E Q-L(0.37)$ followed by $S E Q$ $T(0.20)$. All of these estimated frequencies differ from 0.50 at $p<.01$. In contrast to the simultaneous regime, however, results for the Lenient condition fall closer to the Tough condition than to the Base condition. Looking across treatments, shown in the lower right box of each panel, observe that the difference between $S E Q-T$ and $S E Q-B$ treatments $(-0.59, p<.01)$ and the $S E Q-L$ and $S E Q-B$ treatments $(-0.42, p<.01)$ are quite large, while the difference between the $S E Q-L$ and $S E Q-T$ treatments, while still significantly different from zero, is considerably smaller $(-0.17, p<.01)$. In periods $7-12$, estimated withdrawal frequencies remain essentially unchanged for the $S E Q-L$ treatment (0.35) but rise for $S E Q-B$ (0.87) and fall for $S E Q-T(0.09)$. Again the estimated $S E Q-B$ and $S E Q-T$ frequencies differ from 0.50 at $p<.01$, while the estimated $S E Q-L$ frequency differs from 0.50 at $p<.05$. As a consequence, withdrawal frequencies separate still more distinctly across differences, with $S E Q-B$ exceeding $S E Q-L$ by 0.52 ( $p<.01)$ and $S E Q-L$ exceeding $S E Q-T$ by $0.26(p<.01)$, leaving a $S E Q-B$ to $S E Q-T$ difference of 0.78 ( $p<.01)$. Perhaps most notable is the 0.52 difference between the SEQ-L and SEQ-B treatments, which is much larger than the comparable difference in the simultaneous regime (0.06) and suggests that the symmetric partial run $W H$ equilibrium may have some behavioral drawing power. These comparisons allow statement of a second result.

Result 2: In the sequential (high information) regime, the Lenient re-contracting condition both sizably and significantly improves stability relative to a Base condition. The Tough re-contracting condition still further reduces the probability of unforced withdrawals

Treatment comparisons across information regimes appear in the lower left boxes of each panel in Table 5. In periods 1-6 observe that runs are frequent in the Base condition and not importantly affected by changes in information conditions. Estimated withdrawal frequencies for the $S I M-B(0.83)$ and $S E Q-B$ (0.79) treatments, are high and insignificantly different. Information regime changes more markedly affect outcomes in the Lenient and Tough re-contracting conditions. In the Lenient condition, switching from SIM-L (0.64) to the SEQ-L (0.37) treatment reduces the unforced withdrawal frequency by 0.27 $(p<.0 .01)$, while in the Tough condition a similar switch from SIM-T (0.05) to SEQ-T (0.20) increases the unforced withdrawal frequency by $0.15(p<.0 .01)$. In periods $7-12$ these regime effects persist, with the 
$S I M-B$ to $S E Q-B$ difference remaining virtually unchanged at 0.05 , the $S I M-L$ to $S E Q-L$ difference rising to $0.51(p<0.01)$, and the SIM-T to SEQ-T difference diminishing somewhat to 0.07 but remaining significant $(p<.01)$. We summarize these across treatment comparisons as a third result.

Result 3: The effects of shifting from a simultaneous to a sequential regime vary across recontracting conditions. In the Base condition the shift leaves withdrawal frequencies unaffected. In the Lenient re-contracting condition additional information reduces the frequency of unforced withdrawals, while in the Tough re-contracting condition, additional information slightly increases the frequency of unforced withdrawals.

Result 3 provides an important insight into the effects of information provision in a context where both the degenerate 'run' outcome and the Parteo dominant 'no run' outcomes are equilibria. Rather than exerting an unqualified stabilizing effect as suggested by Schotter and Yorulmazer (2009) and Kiss et al. (2012), the effects of additional information appear to be sensitive to critical features of the underlying game including, in particular, the anticipated response of authorities to financial distress.

\subsection{Morning and Afternoon Withdrawal Behavior in the Sequential Regime.}

The mixed effects of information provision on unforced withdrawal frequencies suggest that some further consideration of how information affects withdrawal behavior is warranted. The previous experimental literature suggests two ways that publicly observable depositor actions might increase stability. First, the awareness by early ('morning') depositors that their actions will be observed by later ('afternoon') depositors may encourage morning hold decisions. ${ }^{29}$ Second and relatedly, the observation of few early withdrawals may encourage afternoon depositors to also hold. ${ }^{30}$ In this subsection we explore these two effects.

Consider first whether the fact that their actions are observable reduces the propensity of patient depositors banking in the morning to withdraw. To assess this effect we repeat the logit estimation in (1), but restrict observations for the sequential regime to the morning decisions of depositors who banked in the morning. Table 6 presents the pertinent cross-treatment comparisons. ${ }^{31}$ As is clear from the table, little suggests that morning depositors in the sequential regime withdraw at a lower frequency than do their counterparts in the simultaneous regime. To the contrary, with the exception of the SEQ-L to SIM- $L$ difference in periods $7-12(-0.18, p<.05)$, withdrawal frequencies are higher for depositors in the

\footnotetext{
${ }^{29}$ See, Kiss et al. (2014a, 2014b). Choi et al. (2006) observe a similar effect in a public goods game.

${ }^{30}$ See Schotter and Yorulmazer (2009) and Kiss et al (2012).

${ }^{31}$ For brevity Table 6 reports only differences across information regimes. Tables A2.1 and A2.2 of Appendix A2 report primary regression results and complete cross treatment comparisons.
} 
sequential treatment. Differences are particularly large for the $S E Q-T$ to $S I M-T$ comparisons in periods 1$6(0.36, p<.01)$. This difference diminishes somewhat with repetition but remains large and significant in periods $7-12(0.19, p<.01)$.

Table 6. Comparing Unforced Morning Withdrawals in the Sequential Regime and All Withdrawals in Simultaneous Regime.

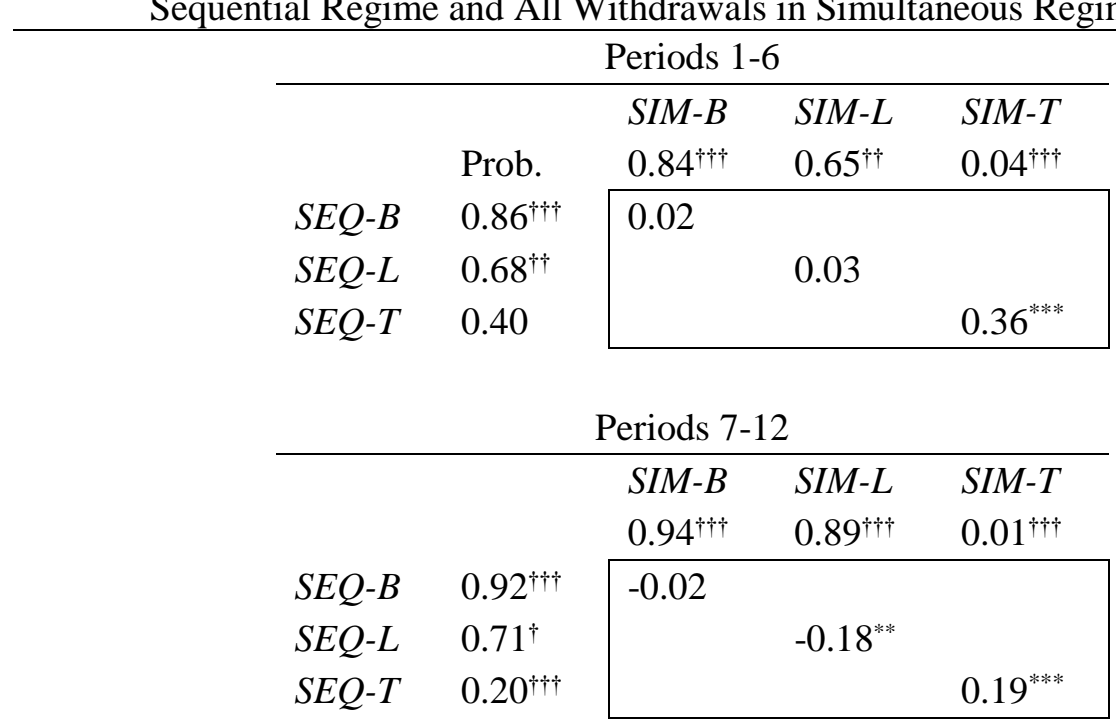

Key: ${ }^{\dagger},{ }^{\dagger \dagger}$ and ${ }^{\dagger \dagger \dagger}$ indicate rejection of null that $\mathrm{p}(\mathrm{w} \mid$ treatment $)=.5$ at $p<.10, .05$ and $.01 .^{*}{ }^{* * *}$ and $^{* * *}$ indicate rejection of the null that treatment $i$ - treatment $j=0$ at $p<.10, .05$ and .01 .

The high propensity of morning depositors to withdraw in the $S E Q-T$ treatment is a primary reason for the comparatively higher withdraw rates overall in the $S E Q--T$ treatment versus the $S I M-T$ treatment: Morning withdrawals are fully half of all unforced withdrawals that occurred in the SEQ-T treatment, suggesting that to a large degree the opportunity to withdraw deposits early provides an appealing measure of security to some depositors. The tendency to withdraw early given the opportunity is particularly appealing to many depositors under the Tough renegotiation stance due to the perceived risk that an afternoon withdrawer could realize a sizable loss, especially were she to fall late in a queue of multiple withdrawers. This risk is much less severe in the Lenient renegotiation stance, consistent with the results in Table 6.

To evaluate the effects of observed initial actions on subsequent withdrawal behavior, we again use a logistic regression, but this time we estimate afternoon withdrawal frequencies for the sequential information regime in light of observed morning withdrawals. Specifically we estimate

$$
\ln \left[\frac{p\left(w_{i j}\right)}{1-p\left(w_{i j}\right)}\right]=\beta_{0}+\beta_{1} D_{B \mid 1}+\beta_{2} D_{T \mid 1}+\beta_{3} D_{L \mid 0}+\beta_{4} D_{T \mid 0}+\beta_{5} D_{B \mid 2}+\beta_{6} D_{L \mid 2}+\beta_{7} D_{T \mid 2}+u_{j}+e_{j i}
$$


where $w_{i j}$ is an unforced afternoon withdrawal by participant $i$ in period $j$. and the $D_{k \mid l}$ are indicator variables that take on a value of 1 when the combination of re-contracting condition $k \in\{B, L, T$, seq $\}$ and morning withdrawals $l \in\{0,1,2\}$ are both true, and 0 otherwise. ${ }^{32,33}$ As with the estimation in (1), we control for repeated measures on individuals by modelling subjects as random effects. Also, as with the previous estimates, we divide the data into two parts (periods 1-6 and periods 7-12) to gain some insight into the effects of repetition.

Tables 7 and 8, summarize pertinent results. ${ }^{34}$ Table 7 reports the effects of observed morning withdrawals $(0,1,2)$ on afternoon withdrawal frequencies. Notice that within treatments, differences in observed morning withdrawals have negligible or minor effects on afternoon decisions. In periods 1-6 none of the within-treatment interactions is significant. In periods 7-12 only a single comparison, the difference between $B \mid 2$ and $B \mid 1$ is significant $(0.22$, $p<.01)$. Otherwise, morning withdrawal differences fail to significantly affect the actions of depositors banking in the afternoon.

However, the across treatment differences, summarized in Table 8, reveal larger and more consistent afternoon differences across re-contracting conditions given observed morning withdrawals. Afternoon withdrawal rates are significantly lower in both the Lenient and Tough re-contracting conditions than in the Base condition. For periods 1-6 given one morning withdrawal the $L \mid 1$ to $B \mid 1$ and $T \mid 1$ to $B \mid 1$ differences are large and significant at $-0.43(p<.01)$ and $-0.62(p<.01)$, respectively. Similarly, two morning withdrawals yield large and significant differences between the $L \mid 2$ to $B \mid 2$ and $T \mid 2$ to $B \mid 2$ treatments, at $-0.55(p<.01)$ and $-0.59(p<.01)$, respectively. For periods $7-12$ the $L \mid 1$ to $B \mid 1$ and $T \mid 1$ to $B \mid 1$ differences are again large and significant at $-0.48(p<.01)$ and $-0.61(p<.01)$, respectively, as are the respective $L \mid 2$ to $B \mid 2$ and $T \mid 2$ to $B \mid 2$ differences, which rise to $-0.66(p<.01)$ and $-0.82(p<.01)$. Notice also that across the

\footnotetext{
${ }^{32}$ Condition $B \mid 0$ is omitted because there were no observations in this cell.

${ }^{33}$ The estimation uses the withdrawal decisions of all depositors who made afternoon decisions. More generally we could separate the decisions of depositors who banked only in the afternoon from those who banked in the morning but decided to not withdraw. The right-hand-side of Tables A2.3, A2.4 and Tables A2.5 and A.2.6 in appendix A2 present detailed regression results and across treatment comparisons for this more general analysis, which do not differ importantly from results of the simpler specification, summary results of which appear below in Tables 7 and 8. The left-hand-side of Tables A2.3 and A.2.4 present detailed regression results for the summary information presented in Tables 7 and 8. Finally, we observe that the AIC (Akaike Information Criterion) value for the simpler model (635.92) is 5.01 units below that of the extended model (640.93), a difference which suggests the simpler model's superiority. See Burnham and Anderson (2002) for a detailed exposition of the use of AIC differences in model selection.

${ }^{34}$ In what follows we truncate the 'SEQ' portion of labels because all treatments are in the sequential information regime.
} 
Lenient and Tough conditions differences are smaller. In periods 1-6, only the $T \mid 1$ to $L \mid 1$ comparison is significant $(-0.19, \mathrm{p}<.05)$. After repetition (i.e., in periods 7-12) the $T \mid O$ to $L \mid O$ difference (-0.26, $p<.01)$, the $T \mid 1$ to $L \mid 1$ difference $(-0.13, p<.05)$, and the $T \mid 2$ to $L \mid 2$ difference ($0.16, p<.01)$, while relatively small, are all significant. We summarize the above observations as a fourth result.

Table 7. Unforced P.M. Withdrawal Frequencies in the Sequential Information Regime: Within Treatment Effects

\begin{tabular}{|c|c|c|c|c|c|c|c|}
\hline & & & & ds $1-6$. & \multirow{5}{*}{$B \mid 1$} & \multirow{5}{*}{$L \mid 1$} & \multirow{5}{*}{$T \mid 1$} \\
\hline & Prob. & $B \mid 0$ & $L \mid O$ & $T \mid O$ & & & \\
\hline$B \mid 1$ & $0.72^{\dagger \dagger}$ & -- & \multirow{3}{*}{0.14} & \multirow[b]{3}{*}{0.03} & & & \\
\hline$L \mid 1$ & $0.29^{\dagger \dagger}$ & -- & & & & & \\
\hline$T \mid 1$ & $0.10^{\dagger \dagger \dagger}$ & -- & & & & & \\
\hline$B \mid 2$ & $0.73^{+1 \dagger}$ & - & \multirow{3}{*}{0.03} & & \multirow[t]{3}{*}{0.01} & \multirow{3}{*}{-0.11} & \\
\hline$L \mid 2$ & $0.18^{\dagger \dagger \dagger}$ & -- & & & & & \\
\hline$T \mid 2$ & $0.14^{+\dagger \dagger}$ & -- & & 0.07 & & & 0.04 \\
\hline \multicolumn{8}{|c|}{ Periods 7-12. } \\
\hline & Prob. & $B \mid 0$ & $F \mid O$ & $N \mid O$ & \multirow[t]{4}{*}{$B \mid 1$} & \multirow[t]{4}{*}{$F \mid 1$} & \multirow[t]{4}{*}{$N \mid 1$} \\
\hline$B \mid 1$ & 0.65 & -- & \multirow{3}{*}{-.13} & \multirow[b]{3}{*}{0.00} & & & \\
\hline$L \mid 1$ & $0.17^{\mathrm{t \dagger i}}$ & -- & & & & & \\
\hline$T \mid 1$ & $0.04^{\dagger \dagger}$ & -- & & & & & \\
\hline$B \mid 2$ & $0.87^{+\dagger}$ & -- & \multirow{3}{*}{-0.09} & & $0.22^{* * * *}$ & \multirow{3}{*}{0.04} & \\
\hline$L \mid 2$ & $0.21^{\dagger \dagger \dagger}$ & -- & & & & & \\
\hline$T \mid 2$ & $0.05^{\mathrm{t \dagger}}$ & -- & & 0.01 & & & 0.01 \\
\hline
\end{tabular}

Key: $k \mid i$, denotes re-contracting condition $k$ given $i$ morning withdrawals. $k \in\{B, F, N\}, \quad i \in\{0,1,2\} . \quad \dagger,{ }^{\dagger \dagger}$ and ${ }^{\dagger \dagger \dagger}$ indicate rejection of null that $\mathrm{p}(\mathrm{w} \mid$ treatment $)=.5$ at $p<.10, .05$ and $.01 .^{*},{ }^{* *}$ and ${ }^{* * *}$ indicate rejection of the null that treatment $i$-treatment $j=0$ at $p<.10, .05$ and .01 .

Result 4: In the sequential information regime, neither the awareness on the part of morning depositors that their actions will be observed nor the observation by afternoon depositors of few morning withdrawals increases stability in our sequential information treatments. Rather withdrawal decisions in the sequential information treatment are more importantly affected by alterations in re-contracting conditions. 
Table 8. Unforced P.M. Withdrawal Frequencies in the Sequential Information Regime, Across Treatment Effects

\begin{tabular}{|c|c|c|c|c|c|c|c|c|}
\hline & \multicolumn{4}{|c|}{ Periods 1-6. } & \multicolumn{4}{|c|}{ Periods 7-12. } \\
\hline & Prob. & $B \mid 0$ & $L \mid O$ & $T \mid O$ & \multirow{4}{*}{$\begin{array}{l}\text { Prob. } \\
\text { NA } \\
0.30 \\
0.04+\dagger\end{array}$} & $B \mid 0$ & $L \mid 0$ & $T \mid 0$ \\
\hline$B \mid 0$ & NA & -- & & & & -- & & \\
\hline$L \mid O$ & $0.15^{\dagger \dagger}$ & -- & -- & & & -- & -- & \\
\hline \multirow[t]{2}{*}{$T \mid 0$} & $0.07+\dagger$ & -- & -0.08 & -- & & -- & $-0.26^{* * *}$ & -- \\
\hline & & $\mathrm{B} \mid 1$ & $\mathrm{~L} \mid 1$ & $\mathrm{~T} \mid 1$ & \multirow[b]{2}{*}{0.65} & $\mathrm{~B} \mid 1$ & $\mathrm{~L} \mid 1$ & $\mathrm{~T} \mid 1$ \\
\hline$B \mid 1$ & $0.72^{\dagger \dagger}$ & -- & & & & -- & & \\
\hline$L \mid 1$ & $0.29^{\dagger \dagger}$ & $-0.43^{* * *}$ & -- & & $0.17^{+\dagger \dagger}$ & $-0.48^{* * *}$ & -- & \\
\hline \multirow[t]{2}{*}{$T \mid 1$} & $0.10^{\dagger \dagger}$ & $-0.62^{* * *}$ & $-0.19^{* *}$ & -- & $0.04^{\dagger \dagger}$ & $-0.61^{* * *}$ & $-0.13^{* *}$ & -- \\
\hline & & $\mathrm{B} \mid 2$ & $\mathrm{~L} \mid 2$ & $\mathrm{~T} \mid 2$ & \multirow[b]{2}{*}{$0.87^{+1 \dagger}$} & $\mathrm{B} \mid 2$ & $\mathrm{~L} \mid 2$ & $\mathrm{~T} \mid 2$ \\
\hline$B \mid 2$ & $0.73^{\dagger \dagger}$ & -- & & & & -- & & \\
\hline$L \mid 2$ & $0.18^{\dagger \dagger}$ & $-0.55^{* * *}$ & -- & & $0.21^{\dagger \dagger}$ & $-0.66^{* * *}$ & -- & \\
\hline$T \mid 2$ & $0.14^{\dagger \dagger}$ & $-0.59^{* * *}$ & -0.04 & -- & $0.05^{\dagger \dagger}$ & $-0.82^{* * *}$ & $-0.16^{* * *}$ & -- \\
\hline
\end{tabular}

The relatively small differences in behavior of afternoon depositors in the SEQ- $L$ and $S E Q-T$ treatments, combined with the considerably higher morning withdrawal probabilities for the $S E Q-L$ treatment shown in Table 6 are consistent with selection of the $W H$ equilibrium in the $S E Q-L$ treatment. Although these results suggest that the $W H$ equilibrium has some behavioral drawing power, play in the $S E Q-L$ treatment does not fully converge on the $W H$ equilibrium. To see this, consider Table 9, which summarizes the incidence of morning and afternoon decisions consistent with the three symmetric Nash equilibria in the sequential regime. In the table, the notation $W(H)$ corresponds to the $W H$ equilibrium, while the notations $H(H)$ and $W(W)$ correspond to the fully efficient and complete run equilibria, respectively. As can be seen from the bolded entries in the Table, observed behavior is perhaps best organized by the full run $W W$ equilibrium in the $S E Q-B$ treatment, the partial run $W H$ equilibrium in the $S E Q-L$ treatment and the efficient no run $H H$ equilibrium in the $S E Q-T$ treatment. Nevertheless, convergence remains incomplete. Even after repetition only $60 \%$ of morning actions and $70 \%$ of afternoon actions are consistent with the $W H$ equilibrium in the $S E Q-L$ treatment. These results lead us to conclude 
that the additional complexity of the sequential treatment adds a behavioral heterogeneity that persistently retards the convergence process. ${ }^{35}$

Notice also in Table 9 the relatively high propensity of morning depositors to withdraw in the $S E Q-T$ treatment, particularly in periods 1-6. As conjectured above, the relatively high propensity of morning depositors to take the certain payment for early withdrawal in the $S E Q-T$ treatment does much to explain the comparatively higher withdrawal frequencies in the $S E Q-T$ treatment relative to the SIM-T treatment. ${ }^{36}$

Table 9. Action Choices Consistent with Symmetric Equilibrium Strategies, Sequential Regime

\begin{tabular}{|c|c|c|c|c|c|c|}
\hline Strategy & \multicolumn{3}{|c|}{ Periods 1-6 } & \multicolumn{3}{|c|}{ Periods $7-12$} \\
\hline & SEQ-B & SEQ-L & SEQ-T & SEQ-B & SEQ- L & SEQ- T \\
\hline $\mathrm{W}(\mathrm{W})$ & $78 \%(71 \%)$ & $60 \%(30 \%)$ & $41 \%(19 \%)$ & $80 \%(78 \%)$ & $60 \%(30 \%)$ & $33 \%(12 \%)$ \\
\hline $\mathrm{W}(\mathrm{H})$ & $78 \%(29 \%)$ & $60 \%(70 \%)$ & $41 \%(81 \%)$ & $80 \%(22 \%)$ & $60 \%(70 \%)$ & $33 \%(88 \%)$ \\
\hline $\mathrm{H}(\mathrm{H})$ & $23 \%(29 \%)$ & $40 \%(70 \%)$ & $59 \%(81 \%)$ & $20 \%(22 \%)$ & $40 \%(70 \%)$ & $68 \%(88 \%)$ \\
\hline
\end{tabular}

Key: Each table entry indicates the percentage of A.M (P.M.) action choices consistent with the strategy appearing in the left column. The bolded entry in each column highlights the strategy for that treatment where behavior is most consistent with the equilibrium.

\section{Conclusion.}

This paper reports an experiment conducted to investigate the potential stabilizing effects of policy alternatives which are practically available to a banking authority when a bank is faced with a solvency crisis that must be resolved via an ex post liquidity suspension, combined with some rescheduling of contract terms. In particular, we study interactions between (a) changes in perceived recontracting postures taken by the banking authority and (b) changes in the level of information about withdrawal behavior available to depositors. We find that re-contracting conditions can importantly affect withdrawal behavior. Starting from a Base condition in a simultaneous move regime where depositors almost uniformly 'run', we find that a Lenient re-contracting condition that skews the terms of repayments toward depositors making withdrawals does virtually nothing to promote stability, while a Tough re-contracting condition that skews the terms of repayments toward those depositors who maintain deposits in the bank reduces almost to zero the incidence of unforced withdrawals.

We further find that information about withdrawals importantly interacts with re-contracting conditions, but not in a uniform way. In particular, relative to a simultaneous regime, where depositors receive no information about others' withdrawal behavior, the provision of information causes the

\footnotetext{
${ }^{35}$ Compare the entries in Table 9, for example, with rates of play in the 'run' and 'no run' outcomes for the simultaneous treatments in Table 6.

${ }^{36}$ In the simpler SIM-T treatment $93 \%$ of actions were consistent with the efficient 'Hold' equilibrium in periods 1 -

6 , and this average increased to $95 \%$ in periods $7-12$.
} 
incidence of withdrawals to fall substantially in a Lenient re-contracting condition, as depositors coordinate on a 'partial run' equilibrium. However, in the Tough re-contracting condition, the shift from a simultaneous to a sequential regime increases the incidence of early unforced withdrawals. In contrast to the Lenient condition, an early withdrawal is quite appealing to many depositors in the Tough recontracting condition, due to the perceived risk that an afternoon withdrawal could result in a sizable loss, especially were she to fall late in a queue of multiple withdrawers.

In summary, our experiment adds two results to this literature. First, a suitably 'Tough' posture toward re-contracting may quite effectively promote stability even if the banking authority cannot commit to an ex ante efficient liquidity suspension. The second result regards the effect of additional information regarding withdrawal behavior. In an environment, where both 'run' and 'no run' outcomes are equilibria the provision of additional information regarding withdrawal behavior is nuanced, and may be strongly dependent on the banking authority's posture toward re-contracting, as well as on the complexity that the additional information adds to the strategic situation faced by depositors.

In closing, we mention two related issues that seem most pressing for future research. The first regards the credibility of a banking authority's re-contracting stance. Informing depositors that a banking authority probabilistically adopts a 'tough' or 'lenient' stance may importantly affect the (de)stabilizing effects of either scheme, even if these probabilities are near unity. The second, related issue regards the effects of depositor experience with run and no run outcomes on regime changes. Previous results in the coordination game literature in general (e.g., Cooper et al. 1990, and Dubois et al. 2012) as well as more specifically in the literature on financial fragility (e.g., Garrett and Keister, 2009 and Trautmann and Vlahu, 2012) suggest that a history of coordinating on either a pareto dominant or on a degenerate outcome importantly affects action choices. It would be well to understand the potential effectiveness of different re-contracting postures in light of experience. A 'tough' re-contracting stance, for example, may far less effectively encourage coordination on the 'no run' outcome than results here suggest, if the stance is preceded by a history of experience with the 'run' outcome. Conversely, a 'lenient' re-contracting posture may be far less susceptible to bank runs in an environment where subjects are accustomed to coordinating on the Pareto dominant 'no run' outcome. Work continues along these lines. ${ }^{37}$

\footnotetext{
${ }^{37}$ We observe, however, that a simplified experimental design, of the type developed by Trautmann and Vlahu (2012) and Brown et al. (2014) may represent a superior platform for examining the questions of policy uncertainty and regime changes.
} 


\section{References}

Arifovic, Jasmina, Janet Hua Jiang and Yiping Xu (2013) "Experimental Evidence of Bank Runs as Coordination Failures, Journal of Economic Dynamics and Control, 37, 2446-2465.

Arifovic, Jasmina, Janet Hua Jiang (2013) "Experimental Evidence of Sunspot Bank Runs" Manuscript, Bank of Canada.

Burnham, Kenneth, and David Anderson (2002) Model Selection and Multimodel Inference: A Practical Information-Theoretic Approach ( $2^{\text {nd }}$ Edition), New York, NY: SpringerVerlag, Inc.

Brown, M., Guin, B., Morkoetter, S. (2013). "Switching costs, deposit insurance and deposit withdrawals from distressed banks.” Working Paper, University of St. Gallen.

Brown, Martin, Stefan T. Trautmann and Razvan Vlahu (2014) "Understanding Bank-Run Contagion ECB Working Paper no. 1711.

Chakravarty, Surajeet., Fonseca, Miquel. A., Kaplan, Todd R. (2014). “An Experiment on the Causes of Bank Run Contagions" European Economic Review, 72, 39-51.

Choi, Syngjoo, Douglas Gale, Shachar Kariv and Thomas Palfrey (2011) Network Architecture, Salience and Coordination," Games and Economic Behavior, 73, 76-90.

Cooper, Russell and Thomas W. Ross (1998) Bank Runs: Liquidity Costs and Investment Distortions" Journal of Monetary Economics 41, 27-38.

Cooper, Russell, Douglas DeJong, Robert Forsythe and Thomas Ross (1990) "Selection Criteria in Coordination Game: Some Experimental Results,” American Economic Review, 80(1), 218 233.

Diamond, Douglas W and Philip H. Dybvig (1983) "Bank Runs, deposit insurance and liquidity" Journal of Political Economy 91, 401-419.

Dubois, Dimitri, Marc Willinger and Phu van Nguyen (2012) “Optimization Incentives and Relative Riskiness in Experimental Coordination Games," International Journal of Game Theory, 41(2), 369-308.

Dufwenberg, Martin, “Banking on Experiments?”, Report, Norwegian Finance Ministry, March 2013

Ennis, Huberto M. and Keister, Todd (2011) Optimal Banking Contracts and Financial Fragility, manuscript, Federal Reserve Bank of Richmond.

Ennis, Huberto M. and Todd Keister (2010a) "Banking panics and policy responses," Journal of Monetary Economics 57, 404-419. 
Ennis, Huberto M. and Keister, Todd (2010b)“'On the Fundamental Reasons for Bank Fragility” Economic Quarterly, Federal Reserve Bank of Richmond 96. 33-58.

Ennis, Huberto M. and Keister, Todd (2009) "Bank Runs and Institutions: The Perils of Intervention" American Economic Review 99, 1580-1607.

Garratt, Rod and Todd Keister (2009) "Bank Runs as Coordination Failures: An Experimental Study" Journal of Economic Behavior and Organization 71, 300-317.

Goldstein, Itay , and Ady Pauzner,(2005) “Demand Deposit Contracts and the Probability of Bank Runs.” Journal of Finance 60, 1293-1327.

Green, Edward J. and Ping Lin (2003) "Implementing efficient allocations in a model of financial intermediation," Journal of Economic Theory 109, 1-23.

Kiss, Hubert Janos, Ismael Rodriguez-Lara and Alfonso Rosa-Garcia (2012) "On the Effects of Deposit Insurance and Observability on Bank Runs: An Experimental Study” Journal of Money Credit and Banking, 44, 1651-1665.

Kiss, Hubert Janos, Ismael Rodriguez-Lara and Alfonso Rosa-Garcia (2014a) "Do Social Networks Prevent Bank Runs? Journal of Economic Behavior and Organization 101, 87-99.

Kiss, Hubert Janos, Ismael Rodriguez-Lara and Alfonso Rosa-Garcia (2014b) "Do Women Panic More than Men? An Experimental Study of Financial Decisions” Journal of Behavioral and Experimental Economics, forthcoming.

Klos, Alexander and Strater, Norbert (2008) "Global Games and Demand-Deposit Contracts: An Experimental Study of Bank Runs MMS, Finance Center Munster.

Ochs, Jack (1995) "Coordination Problems", in John Kagel and Alvin Roth (eds.) Handbook of Experimental Economics, Princeton University Press, 195-252.

Morris, Stephen and Shin, Hyun Song (2001) "Rethinking Multiple Equilibria in Macroeconomic Modelling. NBER Macroeconomics Annual 15, 139-161.

Madiés, Philippe (2006) “An Experimental Exploration of Self-Fulfilling Banking Panices: Their Occurrence, Persistence and Prevention” Journal of Business, 79, 1831-1866

Peck, James and Karl Shell (2003) “Equilibrium bank runs," Journal of Political Economy 111,103-123.

Prescott, Edward Simpson (2010) "Introduction to the Special Issue on the Diamond-Dybvig Model” Economic Quarterly, Federal Reserve Bank of Richmond 96. 1-9.

Schotter, Andrew and Tanjy Yorulmazer (2009) “On the Dynamics and Severity of Bank Runs: An Experimental Study” Journal of Financial Intermediation 18, 217-241. 


\section{Appendices (Not for Publication)}

Appendix A1. Equilibrium Conditions for the WH Strategy in the Sequential Regime.

The intuitive justifications provided in the text for the persistence of the $H H$ and $W W$ equilibria in the sequential regime under contract conditions, and for the nonexistence of an equilibrium using the $H W$ strategy in any contract condition suffice without further comment. Conditions under which the $\mathrm{WH}$ strategy may be an equilibrium, however, are more involved and merit further development. This appendix addresses two pertinent issues. First, we show that under either the base or the Tough re-contracting condition the $W H$ strategy is not an equilibrium, but may be an equilibrium in the Lenient re-contracting condition provided that the probability of selecting urn 1 is sufficiently low. Second, for the lenient condition we identify the critical probability of selecting urn 1 needed to make the $W H$ strategy an equilibrium. We consider these issues in turn.

\section{A.1. Contract Conditions and Equilibrium Existence under the WH Strategy.}

Consider the situation for a representative patient depositor $i$. Label generically, the hold and withdraw payoffs for depositor $i$ as $h_{0, . .,} h_{6}$ and $w_{1 . .,, . .} w_{7}$, as shown in Table A1.1 on the right. Using this general representation of payoffs, Figure A.1 summarizes the game tree for depositor $i$ in the sequential regime, when the other patient players follow a ' $W H$ ' strategy. Starting from the center of the figure nature first selects Urns 1 or 2 with probabilities $r$ and (1$r$ ), respectively. Following urn selection, nature acts again, this time to determine whether depositor $i$ first banks in the p.m. or in the a.m. The left half of the game tree becomes pertinent if the depositor first banks in the afternoon. In this case she chooses either to withdraw Table A1.1. General Payoff Conditions

\begin{tabular}{ccc}
\hline $\begin{array}{c}\text { Withdrawals } \\
\text { (including i) }\end{array}$ & & \\
& $c_{L}$ & $c_{E}$ \\
\cline { 2 - 3 } 0 & $h_{0}$ & -- \\
1 & $h_{1}$ & $w_{1}$ \\
2 & $h_{2}$ & $w_{2}$ \\
3 & $h_{3}$ & $w_{3}$ \\
4 & $h_{4}$ & $w_{4}$ \\
5 & $h_{5}$ & $w_{5}$ \\
6 & $h_{6}$ & $w_{6}$ \\
7 & -- & $w_{7}$ \\
& &
\end{tabular}




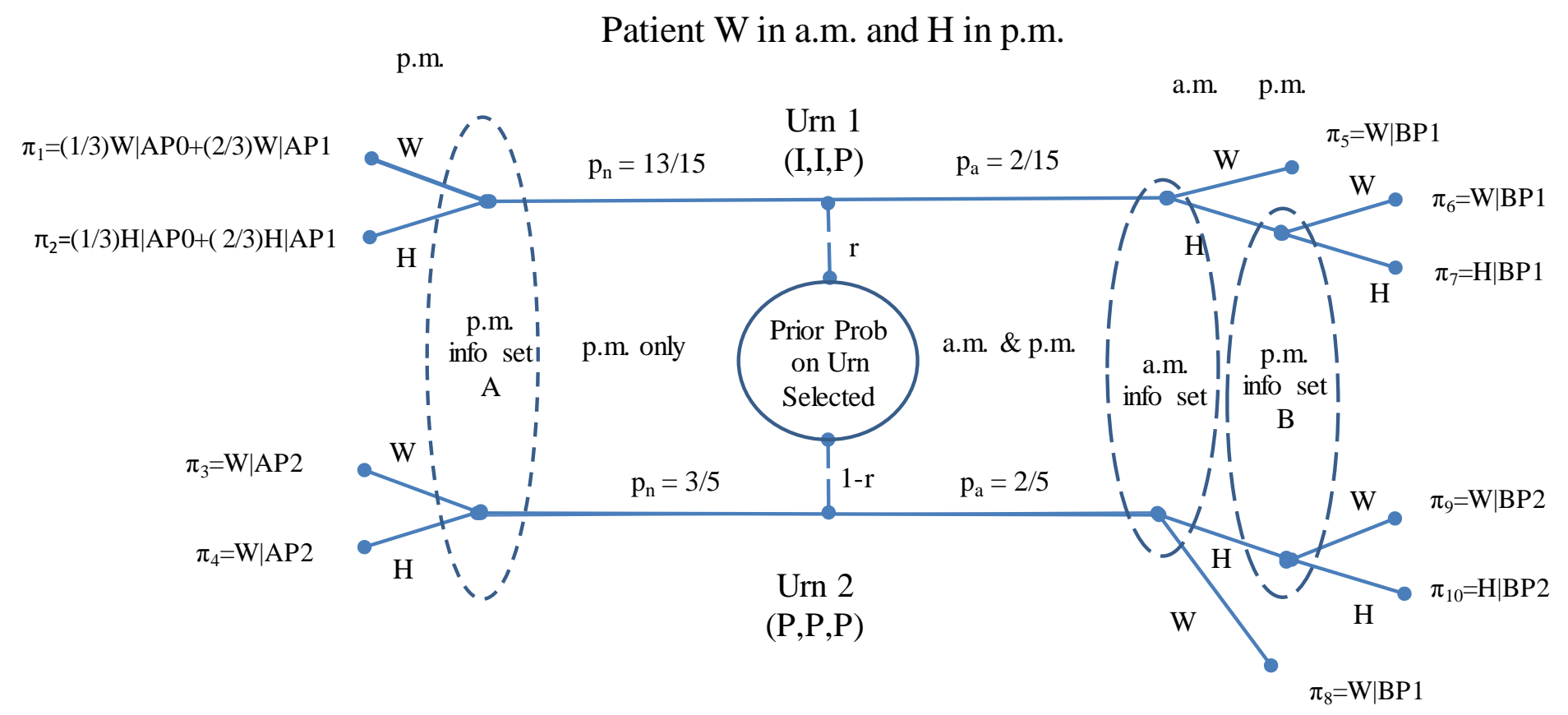

Figure A1. General Payoff Conditions for the WH strategy

If depositor $i$ banks in the morning, the a.m. information set shown as the right half of the game tree is pertinent. She may either play $W$, or play $H$ and wait until the afternoon. In the event she plays $H$, the depositor may again play $W$ or $H$ from information set $B$ in the afternoon, which differs from information set $\mathrm{A}$ in that the depositor knows that either 0 or 1 morning withdrawals have occurred. Expected payoffs for each possible action depend on the urn selected. Consider first afternoon actions in information sets $A$ or $B$. Under the $W H$ strategy, two morning withdrawals will be observed by all depositors banking in the afternoon, and possible payoffs vary with the number of patient depositors withdrawing in the morning. Suppose, for example, that Urn 1 was selected. If the two impatient depositors were subsequently chosen to bank in the morning, then no additional withdrawals would occur in the afternoon, making $h_{2}$ the payoff for $H$ and $w_{3}$ the payoff for $W$. Label this case $A P O$, and the respective payoffs to holding or withdrawing as $W \mid A P O$ and $H \mid A P O$, as summarized in the top row of Table A.1.2. Alternatively, one patient and one impatient depositor may be selected to bank in the morning, a condition we term AP1. As shown in the second row of Table A.1.2, in this case a third withdrawal must occur in the afternoon, making the $H \mid A P 1$ payoff $h_{3}$ and the expected payoff $W \mid A P 1$ payoff $\left(w_{3}+w_{4}\right) / 2$, where the latter payoff is an average, since a withdrawing depositor may be either first or second 
in the afternoon withdrawal queue. Other possible payoff conditions are labeled analogously and detailed explicitly in Table A1.2.

Table A1.2. Possible Afternoon Payoff Conditions under WH Strategy

Depositors Selected to Bank in the p.m. Only

\begin{tabular}{|c|c|c|c|c|c|}
\hline \multirow[t]{2}{*}{$\begin{array}{l}\text { Payoff Condition } \\
\text { Identifier }\end{array}$} & \multicolumn{2}{|c|}{$\begin{array}{c}\text { a.m. } \\
\text { Withdrawals }\end{array}$} & $\begin{array}{l}\text { Remaining } \\
\text { Pool of } \\
\text { Depositors }\end{array}$ & \multicolumn{2}{|c|}{ Expected Payoffs } \\
\hline & $\mathrm{P}$ & $\mathrm{I}$ & $\mathrm{P} \quad \mathrm{I}$ & Hold & Withdraw \\
\hline$A P O$ & $(0$ & 2) & $(5,0)$ & $H \mid A P O: \quad h_{2}$ & $W \mid A P O:$ \\
\hline$A P 1$ & (1 & 1) & $(4,1)$ & $H \mid A P 1: \quad h_{3}$ & $\left(w_{3}+w_{4}\right) / 2$ \\
\hline$A P 2$ & $(2$ & 0) & $(3,2)$ & $H \mid A P 2: \quad h_{4}$ & $W \mid A P 2:\left(w_{3}+w_{4}+w_{5}\right) / 3$ \\
\hline
\end{tabular}

Depositors Selected to Bank in the a.m. But Who Held

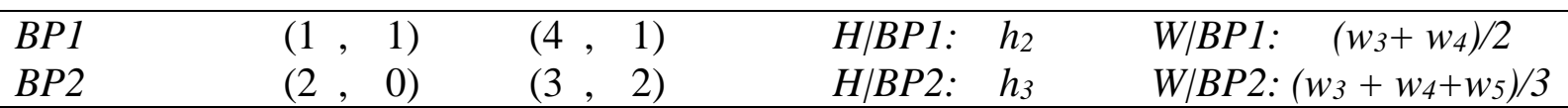

For each action the expected payoff can be determined as the probability-weighted combination of possible payoff conditions for $H$ and $W$ choices given the urn and the decision time (a.m. or p.m.). Figure A.1 illustrates. For example, the upper left corner of Figure A1, displays the expected payoff for a patient depositor choosing to withdraw given that selection of Urn 1 and that she was not selected to bank in the morning. The two morning withdrawals were either both by impatient depositors (which occurs with probability $1 / 3$ ) or by one patient and one impatient depositor (which occurs with probability 2/3). Thus, the expected payoff is (1/3) $W|A P O+(2 / 3) W| A P 1$. Similarly, the expected payoff for a hold action is $(1 / 3) H \mid A P O+(2 / 3)$ $H \mid A P 1$. Expected payoffs for $W$ and $H$ actions at other nodes are calculated similarly.

Parameterized variants of Figure A1 under the Base, and re-contracting conditions; readily allow elimination of the $W H$ strategy as an equilibrium in these cases. In the base condition, shown in Figure A2, notice that regardless of the urn selected a patient depositor increases earnings by deviating from the afternoon action of $H$ : In the case Urn 1 was selected the p.m. only depositor increases her expected earnings $\$ 0.23$ by playing $W$ (with expected earnings of $\$ 0.83$ ) rather than $H$ (with expected earnings of $\$ 0.60$ ). In the case Urn 2 was selected the p.m. only depositor increases her expected earning $\$ 0.32$ by playing $W$ (with expected earnings of $\$ 0.52$ ) rather than $H$ (with expected earnings of $\$ 0.20$ ). 


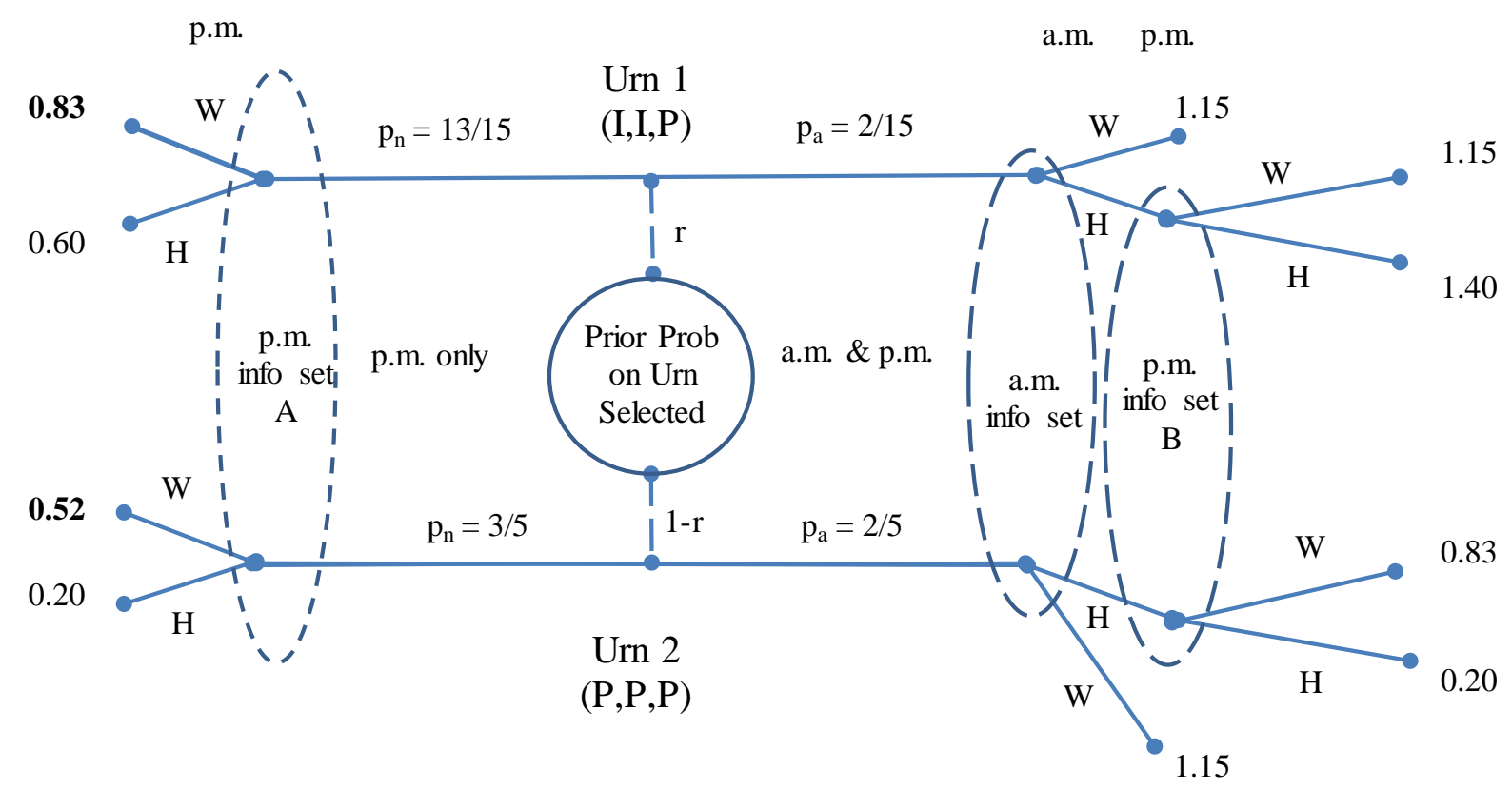

Figure A2. Game Tree for the Sequential Treatment under the WH strategy, parameterized with Base Condition Parameters.

In a similar way inspection of the parameterized payoffs for the Tough condition in Figure A3 allows elimination of $W H$ strategy as an equilibrium in the Tough condition. In this case the unavoidable deviation occurs in the morning. In the case Urn 1 is selected the a.m. depositor increases her expected earnings $\$ 0.25$ by playing $H$ in the a.m. and again $H$ in the p.m. (with expected earnings of \$1.40) rather than $\mathrm{W}$ (with expected earnings of \$1.15). In the case Urn 2 was selected the a.m. depositor increases her expected earnings $\$ 0.05$ by playing $H$ in the a.m. and then $H$ again in the p.m. (for expected earnings of \$1.20) rather than $W$ in the a.m. (with expected earnings of $\$ 1.15)$.

In the Lenient re-contracting condition, the profitability of a deviation is sensitive to the urn chosen. The issue arises with a.m. decisions. As suggested by the bolded entries on the left side of Figure A4, a patient depositor banking only in the afternoon will not deviate from playing $H$ in the afternoon, regardless of the urn selected. The optimal action for a depositor banking in the morning, however, depends on the urn selected. Given the selection of Urn 1, a depositor should deviate by choosing $H$ in the morning and again in the afternoon (in this way increasing expected earnings from $\$ 1.15$ to $\$ 1.40$ ). Given Urn 2, however, deviating from a $W$ action in the a.m.is not profitable, since it would reduce earnings from $\$ 1.15$ to at most $\$ 0.85$. Thus, given the Lenient re-contracting condition, the optimality of the $W H$ strategy depends on the probabilities with which urns 1 and 2 are selected. 


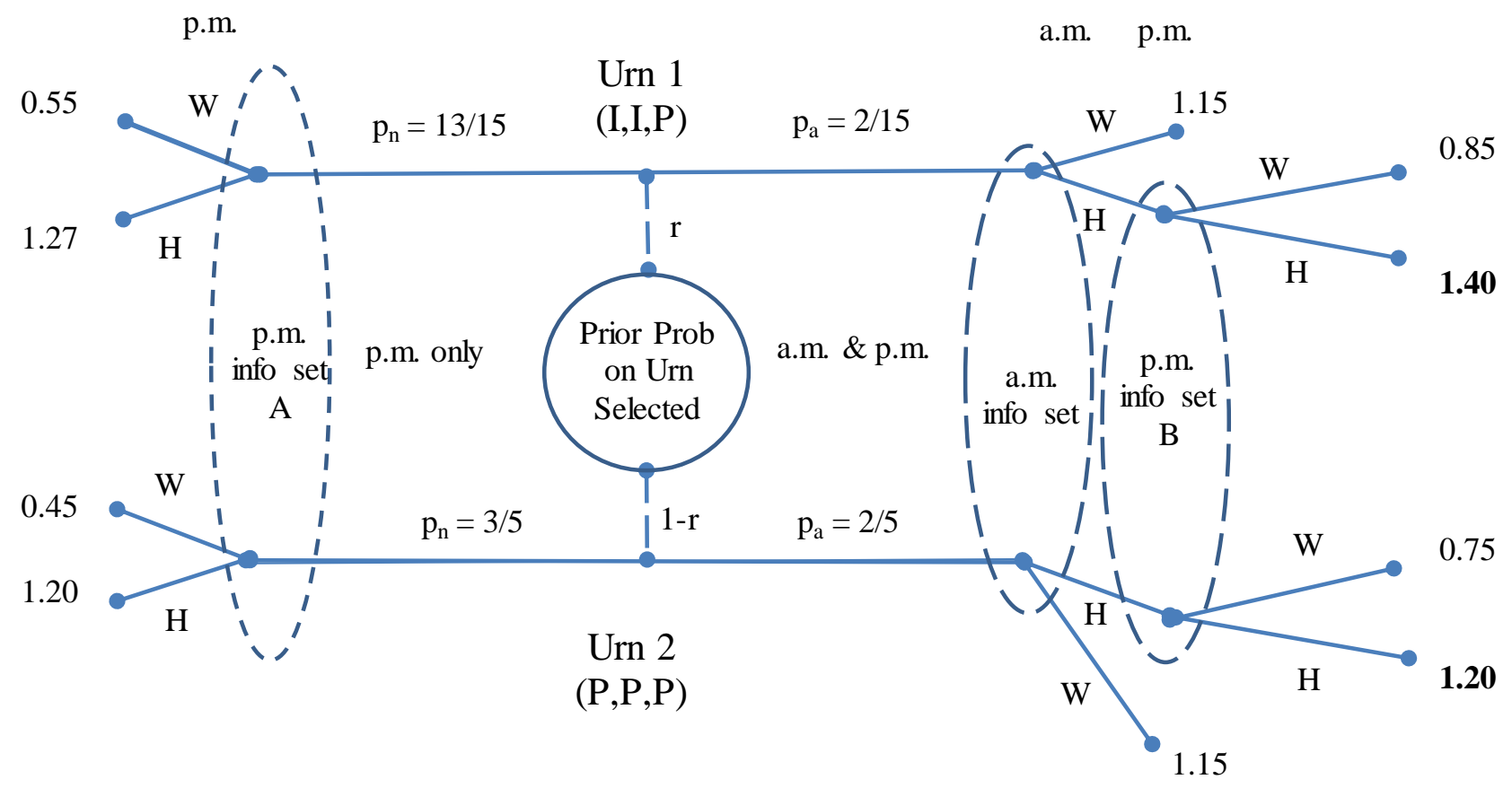

Figure A3. Sequential Game Tree for the $W H$ strategy parameterized with the Tough ReContracting Condition.

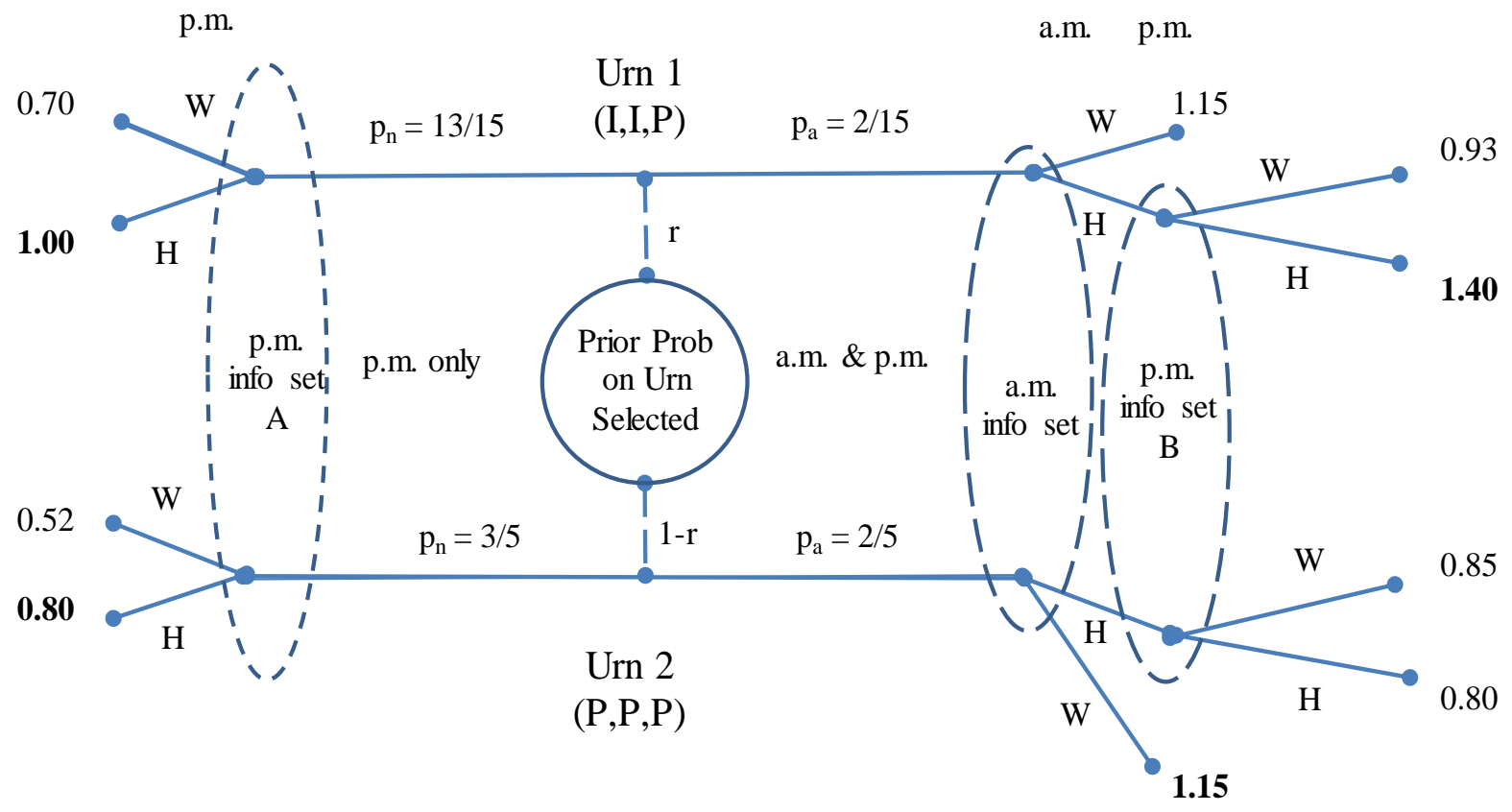

Figure A4. Expected Payoff for WH Strategy under the Lenient Re-Contracting condition. 


\section{A1.2 The Critical Probability of Drawing Urn 1 for HW Equilibrium in in the Lenient Re-} Contracting Condition.

We now identify the critical probability of drawing Urn 2 necessary for the WH strategy to be a Nash equilibrium in the Lenient re-contracting condition. Denote being selected to bank in the morning as ' $a$ '. Then by Bayes theorem

$$
P(U r n 1 \mid a)=\frac{P(a \mid U r n 1) P(U r n 1)}{P(a \mid U r n 1) P(U r n 1)+P(a \mid U r n 2) P(U r n 2)} \text {. }
$$

Referring again to Figure A1, $p(a \mid U r n 1)=2 / 15$ and $p(a \mid U r n 2)=2 / 5=6 / 15$. Labeling the probability of drawing urn 1 as $r$, the critical probability that Urn 1 was selected conditional on a patient depositor being chosen to bank in the a.m. is $g$, or

$$
g \equiv \frac{\frac{2}{15} r}{\frac{2}{15} r+\frac{2}{5}(1-r)}=\frac{\frac{2}{15} r}{\frac{2}{15} r+\frac{6}{15}(1-r)}=\frac{\frac{2 r}{15}}{\frac{6-4 r}{15}}=\frac{2 r}{6-4 r} .
$$

Finally, let ' $a h$ ' denote the event that a depositor banks in the a.m. and plays $\mathrm{H}$ both in the a.m. and again in the p.m. ${ }^{38}$ Given ah only payoff conditions D1|h and D3|h may be realized in the afternoon. These occur with respective probabilities $g$ and $(1-g)$. Thus,

$$
E(H \text { in pm } \mid \mathrm{ah})=P(D 1 \mid a h)(1.40)+P(D 3 \mid a h)(.80)=g(1.40)+(1-g)(0.80)=0.60 g+0.80 \text {. }
$$

This deviation will be profitable only if it exceeds the return from following the strategy and playing $\mathrm{W}$ in morning, yielding a return of $\$ 1.15$, or $0.60 g+0.80>1.15$. Simplifying, $\mathrm{g}>7 / 12$. Thus the critical probability that urn 1 is selected is found by solving $g=\frac{2 r}{6-4 r}>7 / 12$ for $r$. Hence the critical probability for urn 1 is $r<42 / 52=21 / 26=0.81$. Our selection of $r=1 / 2$ for the experiment easily falls within this range.

\footnotetext{
${ }^{38}$ In general we should also consider the probability of a deviation where an a.m. depositor plays $H$ in the a.m. and then $W$ in the p.m. This possibility is irrelevant here, however, because payoffs for an a.m. action of $\mathrm{W}$ always dominate an a.m. action of $\mathrm{H}$ followed by a p.m. action of W. Intuitively, waiting until the p.m. to withdraw cannot increase earnings and may reduce them by pushing the depositor back in the withdrawal queue.
} 
Appendix A2. Estimation Results

Table A2.1. Withdraw Frequency Estimates

\begin{tabular}{|c|c|c|c|c|}
\hline & \multicolumn{2}{|c|}{ All Withdrawals SIM and SEQ } & \multicolumn{2}{|c|}{$\begin{array}{l}\text { All SIM and Morning SEQ } \\
\text { Withdrawals }\end{array}$} \\
\hline & $\begin{array}{c}\text { (1) } \\
\text { Pds. } 1-6\end{array}$ & $\begin{array}{c}\text { (2) } \\
\text { Pds.7-12 }\end{array}$ & $\begin{array}{c}\text { (3) } \\
\text { Pds. 1-6 }\end{array}$ & $\begin{array}{c}\text { (4) } \\
\text { Pds.7-12 }\end{array}$ \\
\hline \multicolumn{5}{|c|}{ Logit Regression Parameter Estimates } \\
\hline$\beta_{0}$ & $\begin{array}{l}1.57^{* * *} \\
(0.23)\end{array}$ & $\begin{array}{l}2.46^{* * * *} \\
(0.32)\end{array}$ & $\begin{array}{l}1.69^{* * * *} \\
(0.27)\end{array}$ & $\begin{array}{l}2.81^{* * *} \\
(0.41)\end{array}$ \\
\hline$\beta_{S I M-L}$ & $\begin{array}{l}-0.98^{* * * *} \\
(0.32)\end{array}$ & $\begin{array}{l}-0.64 \\
(0.44)\end{array}$ & $\begin{array}{c}-1.08^{* * * *} \\
(0.37)\end{array}$ & $\begin{array}{l}-0.67 \\
(0.56)\end{array}$ \\
\hline$\beta_{S I M-T}$ & $\begin{array}{c}-4.56^{* * * *} \\
(0.40)\end{array}$ & $\begin{array}{l}-6.24^{* * *} \\
(0.56)\end{array}$ & $\begin{array}{c}-4.89^{* * * *} \\
(0.46)\end{array}$ & $\begin{array}{c}-7.15^{* * *} \\
(0.71)\end{array}$ \\
\hline$\beta_{S E Q \_B}$ & $\begin{array}{l}-0.24 \\
(0.32)\end{array}$ & $\begin{array}{l}-0.58 \\
(0.43)\end{array}$ & $\begin{array}{c}0.12 \\
(0.50)\end{array}$ & $\begin{array}{l}-0.31 \\
(0.70)\end{array}$ \\
\hline$\beta_{S E Q} L$ & $\begin{array}{l}-2.12^{* * *} \\
(0.31)\end{array}$ & $\begin{array}{c}-3.06^{* * *} \\
(0.42)\end{array}$ & $\begin{array}{c}-0.93^{* *} \\
(0.46)\end{array}$ & $\begin{array}{c}-1.91^{* * *} \\
(0.61)\end{array}$ \\
\hline$\beta_{S E Q} Q_{T}$ & $\begin{array}{l}-2.92^{* * * *} \\
(0.33)\end{array}$ & $\begin{array}{l}-4.80^{* *} \\
(0.45)\end{array}$ & $\begin{array}{c}-2.09^{* * * *} \\
(0.44)\end{array}$ & $\begin{array}{c}4.19^{* * * *} \\
(0.63)\end{array}$ \\
\hline $\begin{array}{c}N \\
\chi^{2}(6)\end{array}$ & $\begin{array}{c}1440 \\
213.5^{* * * *}\end{array}$ & $\begin{array}{c}1440 \\
267.8^{* * * *}\end{array}$ & $\begin{array}{c}912 \\
145.1^{* * *}\end{array}$ & $\begin{array}{c}912 \\
166.5^{* * *}\end{array}$ \\
\hline
\end{tabular}

Withdrawal Frequency Estimates

$\begin{array}{lllll}p(w \mid \text { Sim_B } & 0.83^{\dagger \dagger \dagger} & 0.92^{\dagger \dagger \dagger} & 0.84^{\dagger \dagger \dagger} & 0.94^{\dagger \dagger \dagger} \\ p(w \mid \text { Sim_L } & 0.64^{\dagger \dagger \dagger} & 0.86^{\dagger \dagger \dagger} & 0.65^{\dagger \dagger} & 0.89^{\dagger \dagger \dagger} \\ p(w \mid \text { Sim_T } & 0.05^{\dagger \dagger \dagger} & 0.02^{\dagger \dagger \dagger} & 0.04^{\dagger \dagger \dagger} & 0.01^{\dagger \dagger \dagger} \\ p\left(w \mid S e q \_B\right. & 0.79^{\dagger \dagger} & 0.87^{\dagger \dagger \dagger} & 0.86^{\dagger \dagger} & 0.92^{\dagger \dagger \dagger} \\ p\left(w \mid S e q \_L\right) & 0.37^{\dagger \dagger \dagger} & 0.36^{\dagger \dagger} & 0.68^{\dagger \dagger} & 0.71^{\dagger} \\ p(w \mid S e q-T) & 0.20^{\dagger \dagger \dagger} & 0.09^{\dagger \dagger \dagger} & 0.40 & 0.20^{\dagger \dagger \dagger}\end{array}$

Key: *,** and *** indicate rejection of the null that $\beta_{0}=0$ at $\mathrm{p}<.10, .05$ and .01 , respectively. Each $\mathrm{P}(\mathrm{w} \mid$ treatment $i)$

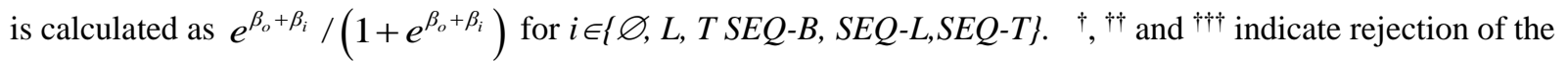
null that $\mathrm{p}(\mathrm{w} \mid$ treatment $)=0.50$ at $p<.10, .05$ and .01 , respectively. 
Table A2.2 Treatment Differences: All SIM and Morning SEQ Withdrawals

\begin{tabular}{|c|c|c|c|c|c|c|c|}
\hline \multicolumn{8}{|c|}{ Periods 1-6 } \\
\hline & Prob. & $S I M-B$ & $S I M-L$ & $S I M-T$ & $S E Q-B$ & $S E Q-L$ & $S E Q-T$ \\
\hline$S I M-B$ & $0.84^{\dagger \dagger \dagger}$ & -- & & & & & \\
\hline$S I M-L$ & $0.65^{\dagger \dagger \dagger}$ & $-0.19^{* * * *}$ & - & & & & \\
\hline$S I M-T$ & $0.04^{\dagger \dagger \dagger}$ & $-0.80^{* * * *}$ & $-0.61^{* * *}$ & -- & & & \\
\hline$S E Q-B$ & $0.86^{\dagger \dagger}$ & 0.02 & & & -- & & \\
\hline$S E Q-L$ & $0.68^{\dagger \dagger}$ & & 0.03 & & $-0.18^{*}$ & & \\
\hline$S E Q-T$ & 0.40 & & & $0.36^{* * * *}$ & $-0.46^{* * *}$ & $-0.28^{* *}$ & \\
\hline
\end{tabular}

Periods 7-12

\begin{tabular}{|c|c|c|c|c|c|c|}
\hline$S I M-B$ & 0.94 & -- & & & & \\
\hline$S I M-L$ & $0.89^{\dagger \dagger \dagger}$ & -0.05 & -- & & & \\
\hline$S I M-T$ & $0.01^{\dagger \dagger \dagger}$ & $-0.93^{* * *}$ & $-0.88^{* * *}$ & -- & & \\
\hline$S E Q-B$ & $0.92^{\dagger \dagger \dagger}$ & -0.02 & \multirow{3}{*}{$-0.18^{* *}$} & & \multirow{3}{*}{\multicolumn{2}{|c|}{$\begin{array}{l}-- \\
-0.21^{* *} \\
-0.72^{* * * *}\end{array}$}} \\
\hline$S E Q-L$ & $0.71^{\dagger}$ & & & & & \\
\hline$S E Q-T$ & $0.20^{\dagger \dagger \dagger}$ & & & $0.19^{* * * *}$ & & \\
\hline
\end{tabular}

Key: ${ }^{\dagger},{ }^{\dagger}$ and ${ }^{\dagger \dagger}$ indicates rejection of the null that $p(w \mid$ treatment $)=0.50$ at $\mathrm{p}<.10, .05$ and .01 , respectively $*, * *$ and $* * *$ indicate rejection of the null that treatment $i$ - treatment $j=0$ at $\mathrm{p}<.10, .05$ and .01 , respectively. 
Table A2.3. Logit Estimates of Afternoon Withdraw Frequencies Conditioned on Observed Morning Withdrawals

\begin{tabular}{|c|c|c|c|c|c|}
\hline & \multicolumn{2}{|c|}{$\begin{array}{l}\text { Pooling returning morning and } \\
\text { afternoon only depositors }\end{array}$} & & \multicolumn{2}{|c|}{$\begin{array}{l}\text { Separating morning and afternoon } \\
\text { only depositors }\end{array}$} \\
\hline & $\begin{array}{c}\text { (1) } \\
\text { Pds. 1-6 }\end{array}$ & $\begin{array}{c}(2) \\
\text { Pds. } 7-12\end{array}$ & & $\begin{array}{c}\text { (3) } \\
\text { Pds. 1-6 }\end{array}$ & $\begin{array}{c}(4) \\
\text { Pds.7-12 }\end{array}$ \\
\hline$\beta_{0}$ & $\begin{array}{l}-0.91^{* *} \\
(0.36)\end{array}$ & $\begin{array}{l}-1.61^{* * *} \\
(0.39)\end{array}$ & & $\begin{array}{l}-0.74^{*} \\
(0.40)\end{array}$ & $\begin{array}{c}-1.39^{* * *} \\
(0.41)\end{array}$ \\
\hline$\beta_{B \mid 1}$ & $\begin{array}{l}1.87^{* * *} \\
(0.50)\end{array}$ & $\begin{array}{l}2.21^{* * * *} \\
(0.56)\end{array}$ & & $\begin{array}{l}1.79^{* * * *} \\
(0.57)\end{array}$ & $\begin{array}{l}2.17^{* * *} \\
(0.61)\end{array}$ \\
\hline$\beta_{T \mid 1}$ & $\begin{array}{l}-1.30^{* *} \\
(0.52)\end{array}$ & $\begin{array}{l}-1.45^{* *} \\
(0.63)\end{array}$ & & $\begin{array}{l}-1.37^{* *} \\
(0.57)\end{array}$ & $\begin{array}{l}-1.45^{* *} \\
(0.67)\end{array}$ \\
\hline$\beta_{B \mid 0}$ & --- & --- & & --- & --- \\
\hline$\beta_{L \mid 0}$ & $\begin{array}{l}-0.86 \\
(0.63)\end{array}$ & $\begin{array}{l}0.75 \\
(0.76)\end{array}$ & & $\begin{array}{l}-1.84^{* *} \\
(0.92)\end{array}$ & $\begin{array}{c}0.23 \\
(1.00)\end{array}$ \\
\hline$\beta_{T \mid 0}$ & $\begin{array}{l}-1.67^{* *} \\
(0.72)\end{array}$ & $\begin{array}{l}-2.52^{* * * *} \\
(0.98)\end{array}$ & & $\begin{array}{l}-1.47^{*} \\
(0.83)\end{array}$ & $\begin{array}{l}-2.19^{* *} \\
(1.01)\end{array}$ \\
\hline$\beta_{B \mid 2}$ & $\begin{array}{l}1.91^{* * *} \\
(0.45)\end{array}$ & $\begin{array}{l}3.55^{* * *} \\
(0.52)\end{array}$ & & $\begin{array}{l}1.75^{* * *} \\
(0.48)\end{array}$ & $\begin{array}{l}3.39^{* * *} \\
(0.53)\end{array}$ \\
\hline$\beta_{L \mid 2}$ & $\begin{array}{l}-0.58 \\
(0.40)\end{array}$ & $\begin{array}{l}0.29 \\
(0.39)\end{array}$ & & $\begin{array}{l}-0.77^{*} \\
(0.43)\end{array}$ & $\begin{array}{c}0.07 \\
(0.41)\end{array}$ \\
\hline$\beta_{T \mid 2}$ & $\begin{array}{l}-0.87^{*} \\
(0.51)\end{array}$ & $\begin{array}{l}-1.42^{* *} \\
(0.69)\end{array}$ & & $\begin{array}{l}-1.06^{*} \\
(0.54)\end{array}$ & $\begin{array}{l}-1.58^{* *} \\
(0.70)\end{array}$ \\
\hline$\beta_{M B \mid 1}$ & & & & $\begin{array}{l}1.48^{* *} \\
(0.76)\end{array}$ & $\begin{array}{l}1.41^{*} \\
(0.85)\end{array}$ \\
\hline$\beta_{M L \mid 1}$ & & & & $\begin{array}{l}-0.85 \\
(0.81)\end{array}$ & $\begin{array}{l}-1.31 \\
(0.94)\end{array}$ \\
\hline$\beta_{M T \mid 1}$ & & & & $\begin{array}{l}-1.99^{* *} \\
(0.95)\end{array}$ & $\begin{array}{l}-2.40^{*} \\
(1.33)\end{array}$ \\
\hline$\beta_{M B \mid 0}$ & & & & --- & --- \\
\hline$\beta_{M L \mid 0}$ & & & & $\begin{array}{l}-0.06 \\
(0.85)\end{array}$ & $\begin{array}{c}0.96 \\
(1.09)\end{array}$ \\
\hline$\beta_{M N \mid 0}$ & & & & $\begin{array}{l}-2.56^{* *} \\
(1.27)\end{array}$ & $\begin{array}{l}-2.39^{*} \\
(1.32)\end{array}$ \\
\hline $\begin{array}{c}N \\
\chi^{2}(8):\end{array}$ & $\begin{array}{l}602 \\
102.6^{* * * *}\end{array}$ & $\begin{array}{l}608 \\
119.1^{* * * *}\end{array}$ & $\chi^{2}(13)$ & $\begin{array}{c}602 \\
102.5^{* * * *}\end{array}$ & $\begin{array}{c}608 \\
120.4^{\text {**** }}\end{array}$ \\
\hline
\end{tabular}

Key: $*, * *$ and $* * *$ indicates rejection of null that $\beta_{k \mid i}=0$ at $\mathrm{p}<.10, .05$ and .01 , respectively. $k \mid t$, denotes morning activity/re-contracting condition $k$ given $t$ morning withdrawals. $k \in\{B, L, T, M B, M L, M T\}, t \in\{0,1,2\}$. ' $M$ ' in models (3) and (4) denotes depositors who banked in the morning but did not withdraw. There are no estimates for $\beta_{B \mid 0}$ and $\beta_{B M \mid 0}$ because there were no pertinent observations in these treatment cells. 
Table A2.4. Probabilities From Logit Estimates of Afternoon Withdraw Frequencies Conditioned on Observed Morning Withdrawals

Pooling returning morning and afternoon only depositors

(1)

Pds. 1-6
(2)

Pds.7-12
Separating morning and afternoon only depositors

(3)

Pds. 1-6

Pds.7-12

\begin{tabular}{|c|c|c|c|c|}
\hline$p(w \mid B O)$ & --- & --- & --- & --- \\
\hline$p(w \mid L O)$ & $0.15^{\dagger \dagger \dagger}$ & 0.30 & $0.07^{\dagger \dagger \dagger}$ & 0.24 \\
\hline$p(w \mid T 0)$ & $0.07^{\dagger \dagger \dagger}$ & $0.02^{\dagger \dagger \dagger}$ & $0.10^{\dagger \dagger \dagger}$ & $0.03^{\dagger \dagger \dagger}$ \\
\hline$p(w \mid B 1)$ & $0.72^{\dagger \dagger \dagger}$ & 0.65 & $0.74^{\dagger \dagger \dagger}$ & $0.69^{\dagger}$ \\
\hline$p(w \mid L 1)$ & $0.29^{\dagger \dagger}$ & $0.17^{\dagger \dagger \dagger}$ & $0.32^{\dagger}$ & $0.20^{\dagger \dagger \dagger}$ \\
\hline$p(w \mid T 1)$ & $0.10^{\dagger \dagger \dagger}$ & $0.04^{\dagger \dagger \dagger}$ & $0.11^{\dagger \dagger \dagger}$ & $0.06^{\dagger \dagger \dagger}$ \\
\hline$p(w \mid B 2)$ & $0.73^{\dagger \dagger \dagger}$ & $0.87^{\dagger \dagger \dagger}$ & $0.73^{\dagger \dagger \dagger}$ & $0.88^{\dagger \dagger \dagger}$ \\
\hline$p(w \mid L 2)$ & $0.18^{\dagger \dagger \dagger}$ & $0.21^{\dagger \dagger \dagger}$ & $0.18^{\dagger \dagger \dagger}$ & $0.21^{\dagger \dagger \dagger}$ \\
\hline$p(w \mid T 2)$ & $0.14^{\dagger \dagger \dagger}$ & $0.05^{\dagger \dagger \dagger}$ & $0.14^{\dagger \dagger \dagger}$ & $0.05^{\dagger \dagger \dagger}$ \\
\hline$p(w \mid B M O)$ & & & --- & --- \\
\hline$p(w \mid L M O)$ & & & 0.31 & 0.39 \\
\hline$p(w \mid T M O)$ & & & $0.04^{\dagger \dagger \dagger}$ & $0.02^{\dagger \dagger \dagger}$ \\
\hline$p(w \mid B M 1)$ & & & 0.68 & 0.51 \\
\hline$p(w \mid L M 1)$ & & & $0.17^{\dagger \dagger}$ & $0.06^{\dagger \dagger \dagger}$ \\
\hline$p(w \mid T M 1)$ & & & $0.06^{\dagger \dagger \dagger}$ & $0.02^{\dagger \dagger \dagger}$ \\
\hline
\end{tabular}

Key: ${ }^{\dagger},{ }^{\dagger \dagger}$ and ${ }^{\dagger \dagger \dagger}$ indicate rejection of null that $\mathrm{p}(\mathrm{w} \mid$ treatment $k i)=.5$ at $\mathrm{p}<.10, .05$ and .01 , respectively. $k \mid t$, denotes morning activity/re-contracting treatment condition $k$ given $t$ morning withdrawals. $k \in\{B, L, T, M B, M L, M T\}, i \in\{0$, $1,2\}$. ' $M$ ' in columns (3) and (4) denotes depositors who banked in the morning but did not withdraw. There are no estimates for $\mathrm{p}(\mathrm{w} \mid \mathrm{B} 0)$ and $\mathrm{p}(\mathrm{w} \mid \mathrm{BM} 0)$ because there were no observations in these cells. Withdrawal probability estimates for each treatment are the ratio $e^{\sum \beta_{i}} /\left(1+e^{\sum \beta_{i}}\right)$ where $\sum \beta_{i}$ denotes the sum of logit regression coefficient estimates that form the treatment estimate. 
Table A2.5. Treatment Differences: Sequential Information Regime. Afternoon Withdrawal Probabilities Conditioned on Observed Morning Withdrawals for Depositors Given Only an Afternoon Withdrawal Opportunity

Periods 1-6.

\begin{tabular}{|c|c|c|c|c|c|c|c|c|c|c|}
\hline & Prob. & $B \mid O$ & $F \mid O$ & $N \mid O$ & $B \mid 1$ & $F \mid 1$ & $N \mid 1$ & $B \mid 2$ & $F \mid 2$ & $N \mid 2$ \\
\hline$B \mid O$ & $N A$ & --- & & & & & & & & \\
\hline$L \mid O$ & $0.07^{\dagger+t}$ & & --- & & & & & & & \\
\hline$T \mid O$ & $0.10^{\dagger+t}$ & & 0.03 & --- & & & & & & \\
\hline$B \mid 1$ & $0.74^{\dagger \dagger}$ & --- & & & --- & & & & & \\
\hline$L \mid 1$ & $0.32^{\dagger}$ & & $0.25^{* *}$ & & $-0.42^{* * *}$ & --- & & & & \\
\hline$T \mid 1$ & $0.11^{\dagger \dagger \dagger}$ & & & 0.01 & $-0.63^{* * *}$ & $-0.21^{* *}$ & --- & & & \\
\hline$B \mid 2$ & $0.73^{\dagger \dagger \dagger}$ & --- & & & -0.01 & & & --- & & \\
\hline$L \mid 2$ & $0.18^{\dagger \dagger \dagger}$ & & 0.11 & & & $-0.14^{*}$ & & $-0.55^{* * *}$ & --- & \\
\hline$T \mid 2$ & $0.14^{\dagger \dagger \dagger}$ & & & 0.04 & & & 0.03 & $-0.59^{* * *}$ & -0.04 & --- \\
\hline
\end{tabular}

Periods 7-12.

\begin{tabular}{|c|c|c|c|c|c|c|c|c|c|c|}
\hline & Prob. & $B \mid 0$ & $F \mid O$ & $N \mid O$ & $B \mid 1$ & $F \mid 1$ & $N \mid 1$ & $B \mid 2$ & $F \mid 2$ & $N \mid 2$ \\
\hline$B \mid 0$ & $N A$ & --- & & & & & & & & \\
\hline$L \mid O$ & 0.24 & & --- & & & & & & & \\
\hline$T \mid 0$ & $0.03^{t \dagger t}$ & & $-0.21^{*}$ & --- & & & & & & \\
\hline$B \mid 1$ & $0.69^{\dagger}$ & --- & & & --- & & & & & \\
\hline$L \mid 1$ & $0.20^{\dagger \dagger t}$ & & -0.04 & & $-0.49^{* * *}$ & --- & & & & \\
\hline$T \mid 1$ & $0.06^{\dagger \dagger t}$ & & & 0.03 & $-0.63^{* *}$ & $-0.14^{* *}$ & --- & & & \\
\hline$B \mid 2$ & $0.88^{\dagger \dagger}$ & --- & & & $0.19^{* *}$ & & & --- & & \\
\hline$L \mid 2$ & $0.21^{\dagger \dagger \dagger}$ & & -0.03 & & & 0.01 & & $-0.67^{* * *}$ & --- & \\
\hline$T \mid 2$ & $0.05^{\dagger \dagger}$ & & & 0.02 & & & -0.01 & $-0.83^{* * *}$ & $-0.16^{* *}$ & --- \\
\hline
\end{tabular}

Key: ${ }^{\dagger},{ }^{\dagger \dagger}$ and ${ }^{\dagger \dagger \dagger}$ indicate rejection of null that $\mathrm{p}(\mathrm{w} \mid$ treatment $k \mid t)=.5$ at $\mathrm{p}<.10, .05$ and $.01 . k \mid t$, denotes recontracting condition $k$ given $t$ morning withdrawals. $k \in\{B, L, T\}, i \in\{0,1,2\}$.

$*, * *$ and $* * *$ indicate rejection of the null that treatment $i$ - treatment $j=0$ at $\mathrm{p}<.10, .05$ and .01 . 
Table A2.6. Treatment Differences: Sequential Information Regime. Afternoon Withdrawal Probabilities Conditioned on Observed Morning Withdrawals for Depositors who Banked in the Morning but did not withdraw.

Periods 1-6

\begin{tabular}{|c|c|c|c|c|c|c|c|}
\hline & Prob. & $B M \mid 0$ & $L M \mid O$ & $T M \mid 0$ & \multirow[t]{4}{*}{$B M \mid 1$} & \multirow[t]{4}{*}{$L M \mid 1$} & \multirow[t]{4}{*}{$T M \mid 1$} \\
\hline$B M \mid O$ & NA & \multirow[t]{3}{*}{-- } & & & & & \\
\hline$L M \mid O$ & 0.31 & & -- & & & & \\
\hline$T M \mid O$ & $0.04^{\dagger \dagger \dagger}$ & & $-0.27^{*}$ & -- & & & \\
\hline$B M \mid I$ & 0.68 & & \multirow{3}{*}{-0.14} & & -- & & \\
\hline$L M \mid 1$ & $0.17^{\dagger \dagger}$ & & & & $-0.51^{* *}$ & $--M$ & \\
\hline$T M \mid 1$ & $0.06^{\dagger \dagger \dagger}$ & & & 0.02 & $-0.62^{* * * *}$ & -0.11 & -- \\
\hline
\end{tabular}

Periods 7-12

\begin{tabular}{|c|c|c|c|c|c|c|c|}
\hline & Prob. & $B M \mid 0$ & $L M \mid O$ & $T M \mid O$ & $B M \mid 1$ & $L M \mid 1$ & $T M \mid 1$ \\
\hline$B M \mid O$ & NA & -- & & & & & \\
\hline$L M \mid O$ & 0.39 & & - & & & & \\
\hline$T M \mid O$ & $0.02^{\dagger \dagger \dagger}$ & & $-0.37^{* *}$ & -- & & & \\
\hline$B M \mid I$ & 0.51 & -- & & & -- & & \\
\hline$L M \mid I$ & $0.06^{\dagger \dagger \dagger}$ & & $-0.33^{*}$ & & $-0.45^{* *}$ & --- & \\
\hline$T M \mid 1$ & $0.02^{\dagger \dagger \dagger}$ & & & 0.00 & $-0.49^{* * * *}$ & -0.04 & -- \\
\hline
\end{tabular}

Key: ${ }^{\dagger},{ }^{\dagger \dagger}$ and ${ }^{\dagger \dagger}$ indicate rejection of null that $\mathrm{p}(\mathrm{w} \mid$ treatment $k t)=.5$ at $\mathrm{p}<.10, .05$ and $.01 . k \mid t$, denotes re-contracting condition $k$ given $i$ morning withdrawals. $k \in\{B M, L M, T M\}, i \in\{0,1,2\}$. *,* and $* * *$ indicate rejection of the null that treatment $i$ - treatment $j=0$ at $\mathrm{p}<.10, .05$ and .01 , respectively. 
Appendix A3. Sample Instructions.

The following instructions are for the base condition in the sequential information regime. Instructions for the other sequential treatments are identical except that payoff tables are changed as indicated in Table 2 of the text. The corresponding instructions for the simultaneous regime are available at http://www.people.vcu.edu/ dddavis

\section{Instructions}

Welcome! This is an experiment in decision-making. Funding for this experiment has been provided by the National Science Foundation and Virginia Commonwealth University. For today's session, you will receive a \$6 show-up fee. In addition, you will have the opportunity to earn money during the session.

Your decisions are likely to considerably affect your earnings. If you follow the instructions carefully and make good decisions, you can earn a considerable amount of money.

Caution: Talking, looking at others' screens, or exclaiming aloud is not allowed. Should you have any questions please raise your hand and an experimenter will come to you.

1. Session Structure. Today's session consists of one sequence, which will consist of 14 periods or days. The first 2 days will be unpaid practice periods. In each of the remaining 12 days you will be paid for your decisions. At the beginning of each day, you will be matched with six decision-makers. Four of these decision-makers are randomly selected other participants seated in this room. The remaining two decision-makers are computerized and make mechanical choices, which we describe in a moment.

Each day in this sequence you will be matched with a new group. We will refer to the decisionmakers you are matched with in a given sequence, including the two computerized decisionmakers, as OTHERS.

2. Problem Overview. In today's experiment, you and each of the others is endowed with a token that is deposited in a bank. You are to make HOLD or WITHDRAW decisions for this token. If you HOLD the token in deposit until the end of a "day" you will receive a payoff in column (2); if you WITHDRAW it you will receive a payment in column (3).

\begin{tabular}{ccc}
\hline $\begin{array}{c}(1) \\
\begin{array}{c}\text { Number of Withdrawals } \\
\text { By OTHERS }\end{array}\end{array}$ & $\begin{array}{c}(2) \\
\text { HOLD } \\
\text { Payoff }\end{array}$ & $\begin{array}{c}(3) \\
\text { WITHDRAW } \\
\text { Payoff }\end{array}$ \\
\hline 0 & $\$ 1.40$ & $\$ 1.15$ \\
1 & $\$ 1.40$ & $\$ 1.15$ \\
2 & $\$ 1.40$ & $\$ 1.15$ \\
3 & $\$ 0.20$ & $\$ 0.20$ \\
4 & $\$ 0.20$ & $\$ 0.20$ \\
5 & $\$ 0.20$ & $\$ 0.20$ \\
6 & $\$ 0.20$ & $\$ 0.20$ \\
\hline
\end{tabular}


HOLD and WITHDRAW payoffs depend on the Number of Withdrawals by OTHERS in column (1). The Number of OTHER withdrawals affects HOLD and WITHDRAW payoffs differently. The payoff for WITHDRAW depends on your order in line of depositors who withdrew funds. The payoff for HOLD depends on the total number of withdrawals by the end of the day. Importantly, however, the two automated depositors mechanically withdraw when given the chance. Thus at the end of the day there will always be at least two WITHDRAW decisions by OTHERS.

\section{Daily Tasks Each day consists of two parts, a morning, and an afternoon.}

a) Morning Decisions. At the beginning of the morning, two depositors are randomly selected and given an opportunity to 'bank', or make an early HOLD/WITHDRAW decision. We note two important features of morning decisions.

1) Depositors are not chosen with equal probabilities. Rather the two depositors that may bank in the morning are drawn (without replacement) from one of two "urns", which are made up anew each day. The composition of the two urns is as follows:

a. For Urn 1: One human depositor is randomly selected from the five human depositors and combined with the two automated 'impatient' depositors, who will automatically withdraw whenever given the opportunity.

b. For Urn 2: Three human depositors are randomly selected from the five human depositors.

Each day, the computer picks urn 1 with a probability of $50 \%$. Essentially, the computer 'tosses a coin'. If the coin lands heads up, urn 1 is used. If the coin lands tails up, urn 2 is used. You will not be told which urn is being used on a particular day.

2) Any depositor who banks in the morning and HOLDs will also be given an opportunity to bank again in the afternoon.

b) Afternoon Decisions. Unless she withdrew in the morning each depositor will bank in the afternoon and make a HOLDMITHDRAW decision at that time.

Once afternoon decisions are complete, depositors are randomly ordered, and payoffs are determined by (i) the total number of withdrawals and, if the depositor decided to withdraw (ii) her order in the queue of those who withdrew.

\section{Specific Instructions}

a) Morning Decisions.

Figure 1 illustrates the screen display for a participant 3 in the morning of period 2.

In the morning a participant is either selected to bank or not. Figure 1 shows the case where participant 3 is selected to bank in the morning.

Question: Can you tell which urn was used this period? Explain.

Participant 3 must make a forecast and then make a HOLD/ WITHDRAW decision. She forecasts (1) whether or not the other depositor selected in the morning will withdraw, and (2) the number of additional withdrawals by OTHERS that will take place in the afternoon $(1,2,3,4$, 5 , or 6 ). Note that participant 3's morning and afternoon withdrawal forecasts must sum to at least 2. 
Probability of Um 1 ( 2 automated and 1 human depositor): $50 \%$ Probability of Urn 2 ( 3 human depositors): $50 \%$

ID: $\quad$ Day

\begin{tabular}{|ccc|}
\hline & Payoffs & \\
\hline Number of Withdrawals by Others & HOLD & WITHDRAW \\
0 & $\$ 1.40$ & $\$ 1.15$ \\
1 & $\$ 1.40$ & $\$ 1.15$ \\
2 & $\$ 1.40$ & $\$ 1.15$ \\
3 & $\$ 0.20$ & $\$ 0.20$ \\
4 & $\$ 0.20$ & $\$ 0.20$ \\
5 & $\$ 0.20$ & $\$ 0.20$ \\
6 & $\$ 0.20$ & $\$ 0.20$ \\
\hline
\end{tabular}

'ou ARE selected to bank in the moming. Please make forecast decisions and press 'lllustrate'. Then make a decision when ready.

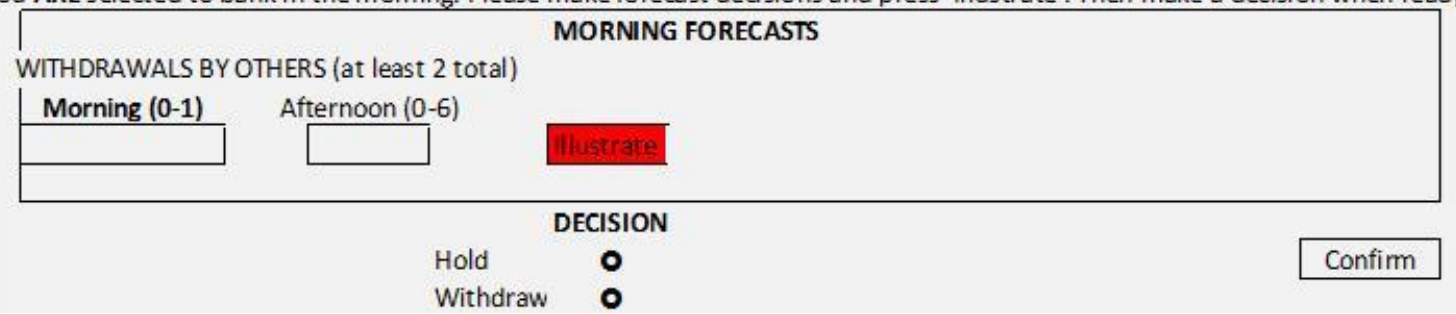

$\overline{\text { Figure 1. Screen Display for a Participant } 3 \text { Selected to Bank in the Morning of Period } 2 .}$

Combined, morning and afternoon withdrawal forecasts will imply a forecasted HOLD Payoff projection. Figure 2. Illustrates the case where participant 3 forecasts that the other depositor selected to bank in the morning will choose WITHDRAW and that two other depositors will also subsequently withdraw in the afternoon. If her forecast is correct, in the case she WITHDRAWs, she will be either first or second in the queue of morning withdrawals and will earn $\$ \mathbf{1 . 1 5}$. Again if her forecast is correct, if she HOLDs participant 3 will earn $\$ \mathbf{0 . 2 0}$, as indicated by the bolded blue entry in the HOLD column.

Probability of Urn 1 ( 2 automated and 1 human depositor): 50\% Probability of Urn 2 (3 human depositors): 50\%

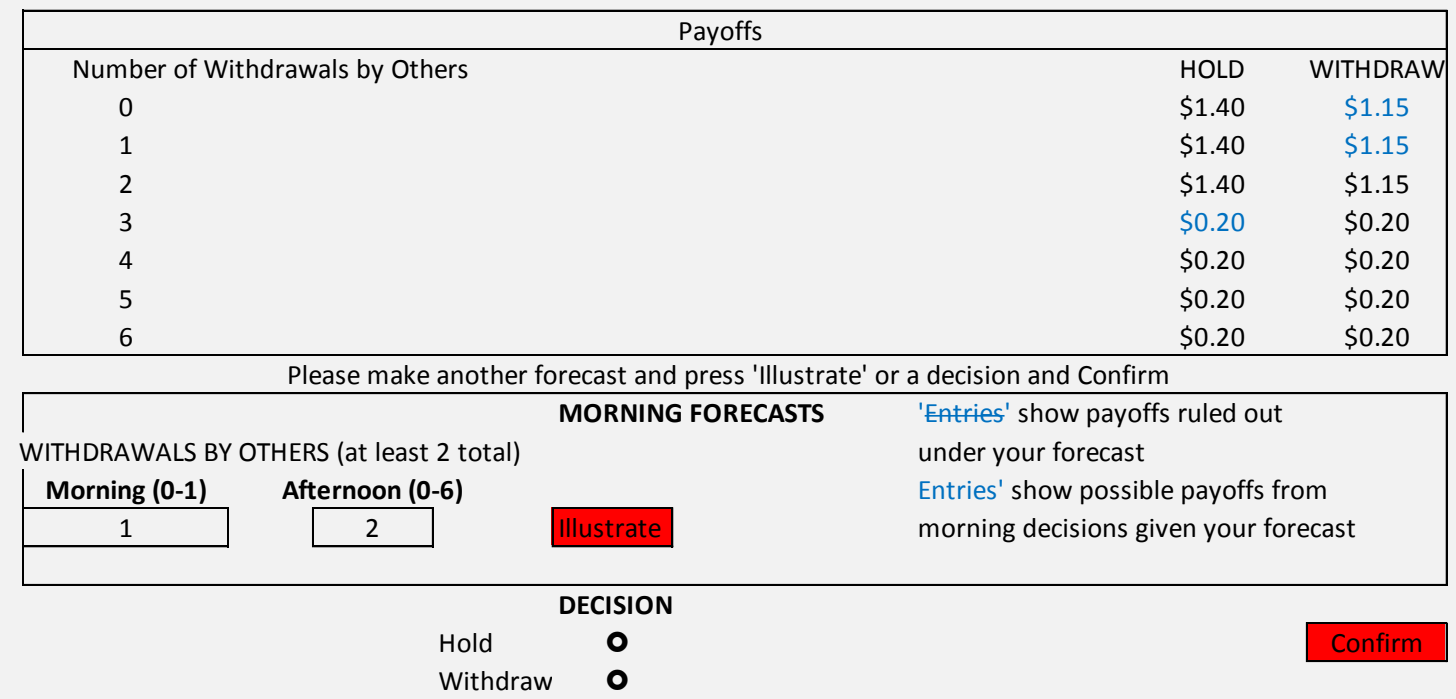

Figure 2. Screen display for a depositor selected to bank in the morning after making a forecast. 
Question: Suppose participant 3 forecasts 0 OTHER morning and 4 OTHER afternoon WITHDRAW decisions. What are her forecast earnings in this case?

Importantly, these are only forecast outcomes. Participant 3's payoffs will be determined by the actual HOLD/WITHDRAW decisions of the other depositors.

In any day, you may try several forecast combinations if you like. Following your forecasts, you must make a HOLD/WITHDRAW decision by clicking on a radial dial, and then CONFIRM your choice. You have 30 seconds to make your decisions.

Figure 3 shows the lower portion of the screen for a depositor who was NOT selected to bank in the morning. In this case the depositor makes no morning decision, but still must forecast the number of withdrawals by OTHERS that will occur in the morning $(0,1$ or 2$)$ and afternoon $(0,1$, $2,3,4,5$, or 6 ).

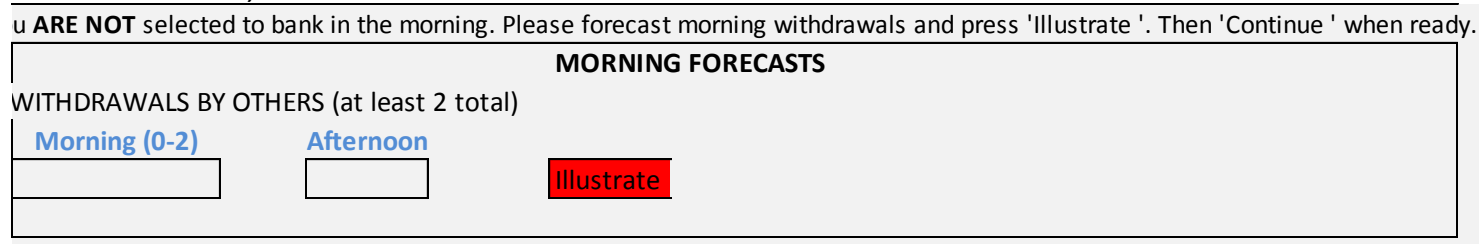

Figure 3. Screen Display for a Depositor Not Selected to Bank in the Morning of Day 2.

Question: Why is 2 the maximum allowed forecast of morning withdrawals?

Question: Why must you forecast at least 2 total OTHER withdrawals?

b) Afternoon Actions. In the afternoon a participant gets an information update, makes a forecast, and then make a HOLD/WITHDRAW decision.

Information update. Once morning decisions are complete, the screen updates to reflect results of morning decisions. Figure 4 illustrates a case where two OTHER withdrawals occurred in the morning. As indicated in the table, if zero additional depositors withdraw in the afternoon, the return to holding will be $\$ 1.40$. A third depositor to WITHDRAW will earn $\$ \mathbf{1 . 1 5}$.

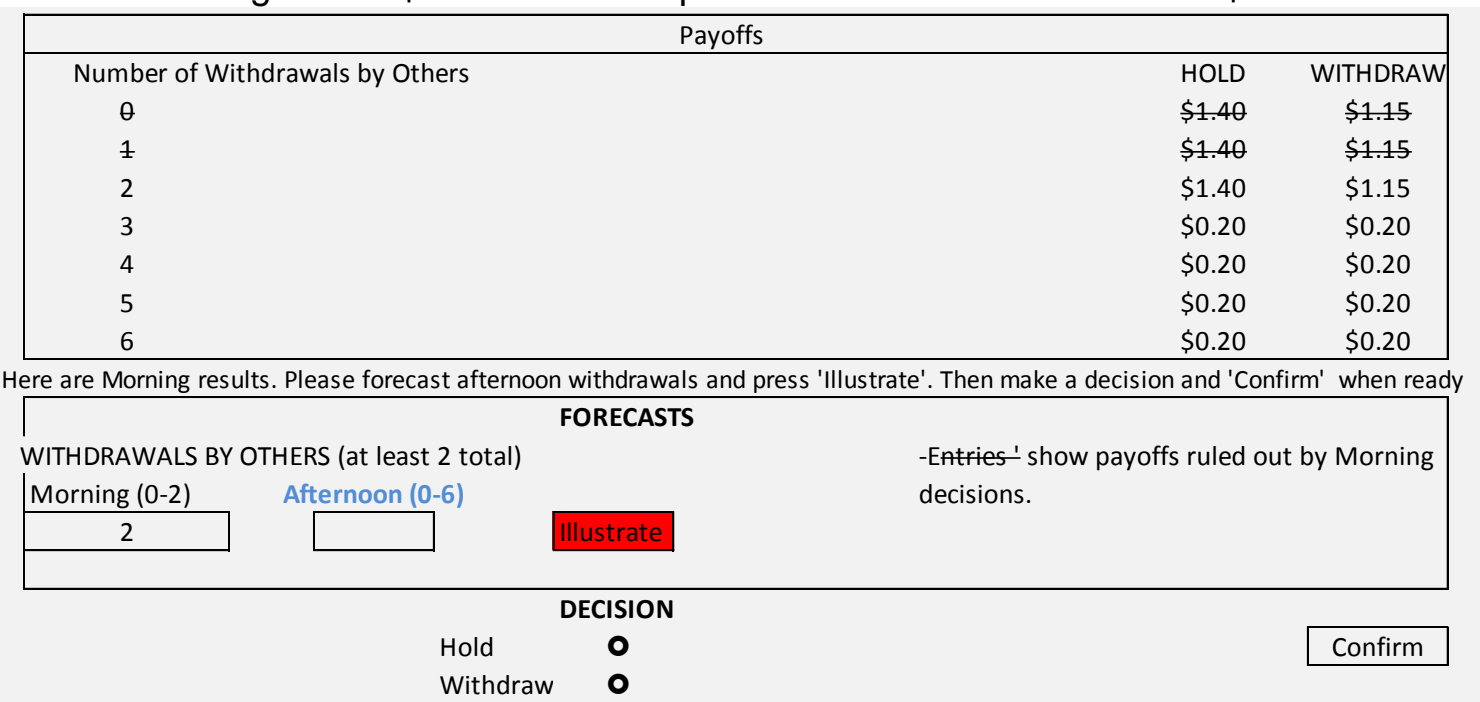

Figure 4. Payoff Table after Two Morning Withdrawals. 
Question: How would Figure 4 change if only 1 person played WITHDRAW in the morning?

Notice also, however, that each day at least 5 depositors make afternoon decisions, and payoffs depend on the decisions of others. In Figure 4, for example, if two additional OTHERs WITHDRAW in the afternoon, then the payoff to HOLD would be $\mathbf{\$ 0 . 2 0}$, as shown on the row for 4 Withdrawals by Others. The payoff to WITHDRAW depends on the order that a withdrawing depositor is selected. In this example, if a depositor is the $1^{\text {st }}$ selected in the afternoon and WITHDRAWs, she will earn $\$ \mathbf{1 . 1 5}$. If she is the $2^{\text {nd }}$ or $3^{\text {rd }}$ selected and withdraws, she will earn $\$ 0.20$.

Question: In Figure 4, what would participant 3's earnings options for HOLD and WITHDRAW if there was only 1 additional OTHER afternoon withdrawal?

Forecasts. Every depositor who did not withdraw in the morning forecasts the number of OTHER withdrawals that he expects in the afternoon. Figure 5 illustrates the afternoon decision in the case of a depositor who forecasts a total of three additional afternoon withdrawals by OTHERS after observing two withdrawals in the morning. If her forecast proves correct, she will earn $\$ 0.20$ from a HOLD decision as shown in blue. If she WITHDRAWs, her earnings depend on the order in which she is chosen. She could be the $1^{\text {st }}$ selected and earn $\$ 1.15$ or be the $2^{\text {nd }}$, $3^{\text {rd }}$ or $4^{\text {th }}$ selected and earn $\$ \mathbf{0 . 2 0}$, all with equal likelihood.

You may try several forecasts, but you have only 30 seconds to complete your decision.

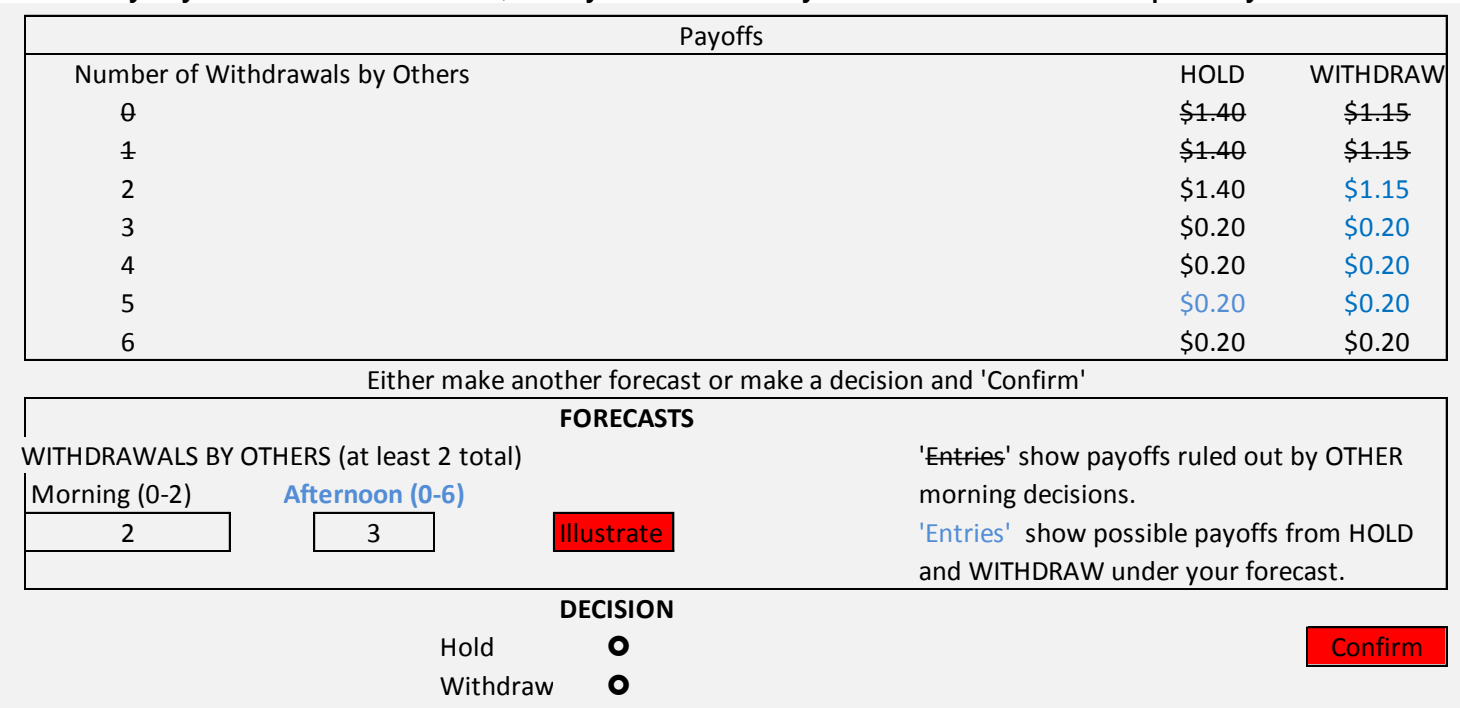

Figure 5. Afternoon forecasts and decisions.

Decisions. As seen in Figure 5, the participant must also make a HOLD/WITHDRAW decision. Once you have settled on a forecast, click HOLD or WITHDRAW and then CONFIRM your selection.

c). Results. Once all afternoon decisions are complete, a participant's order in sequence, and her actual HOLD and WITHDRAW payoffs are determined. Figure 6 shows the case of a participant who forecast a total of 5 OTHER withdrawals, and chose also to WITHDRAW. However, as indicated by the bolded entry in the table, only 4 OTHER depositors in total (and two in the afternoon). Also, Participant 2 was the second person in the afternoon queue and so 
earned \$0.20 from her decision to WITHDRAW, as highlighted by the bolded payoff in the WITHDRAW column.

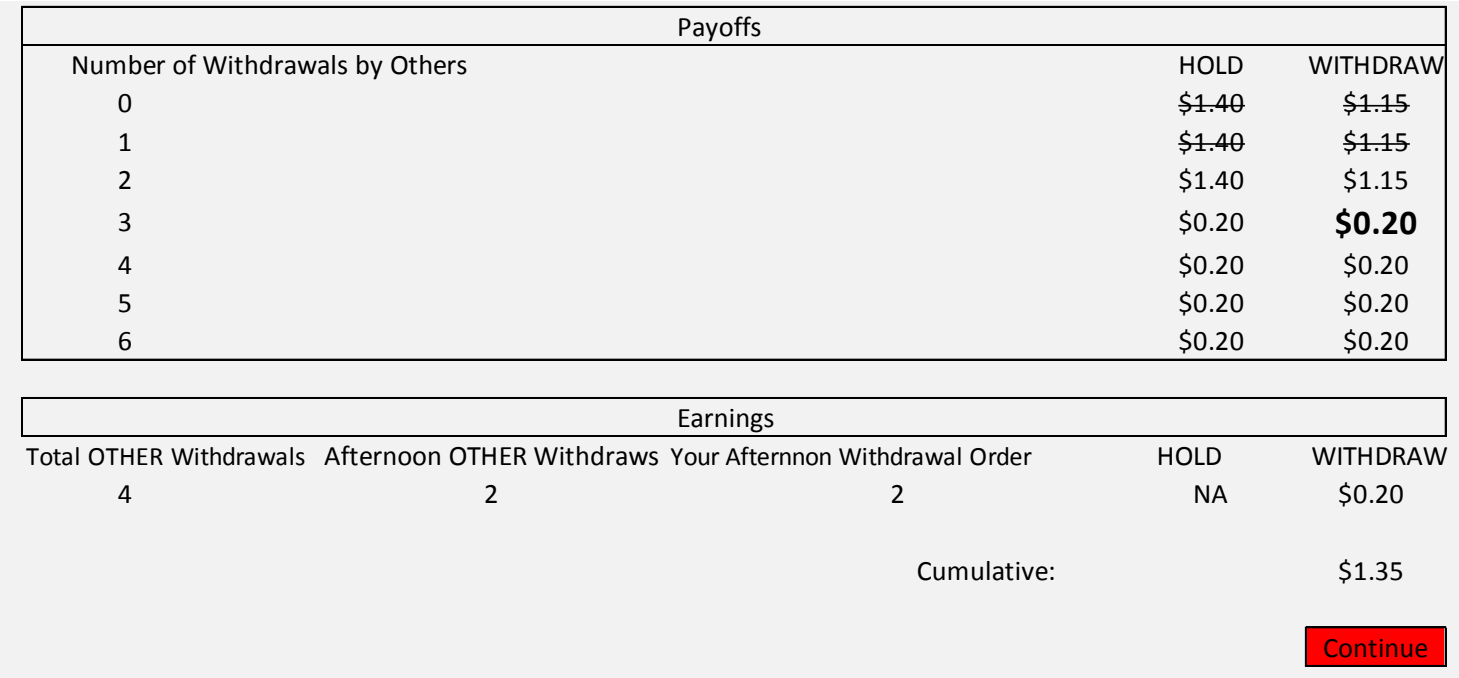

Figure 6. Outcomes and Earnings Calculations

Notice also in Figure 6 that cumulative earnings from the session are maintained. After reviewing results, click CONTINUE to proceed to the next period.

\section{Summary:}

- Each day, you are a depositor in a new group with 6 other depositors

- 4 OTHER depositors are human, and the remaining 2 are automated

- Each depositor is endowed with a token that they may either HOLD until afternoon or WITHDRAW early.

○ The 2 automated depositors WITHDRAW whenever they get the chance

- 2 depositors (one of whom could be you) will be given the opportunity to make a HOLD/WITHDRAW decision in the morning.

- With probability $1 / 2$ the two morning bankers will be selected from an urn 1 , consisting of the two automated depositors and one human depositor

- With probability $1 / 2$ the two morning bankers will be selected from an urn 2, consisting of three human depositors.

- Your earnings from a HOLD decision are determined by the number of OTHER people who WITHDRAW prior to the end of the afternoon.

- Your earnings from WITHDRAW depend on whether you go to the bank in the morning or afternoon.

○ In the morning you earn $\$ 1.15$ from a WITHDRAW decision

$\circ$ In the afternoon, your earnings from a WITHDRAW decision depend on your position in the sequence of those who WITHDRAW in the afternoon.

- Other information

- We begin with 2 practice periods for which you will not be paid 
- The practice periods will be followed by a sequence that will consist of 12 decision days. Then the experiment will end and you will be paid the sum of your earnings.

- Your lab currency earnings will be converted to US currency at a 1 to 1 rate.

\section{Quiz of Understanding}

1) In day 4, will the membership of OTHERs in your group be the same or different as in day 3 ?

2) Suppose that you ARE selected to bank in the morning.

a. If you are selected to bank in the morning, does that mean that urn 2 was used?

b. How much will you earn from an immediate WITHDRAW decision?

c. At a maximum how many OTHER WITHDRAW decisions may occur in the morning?

d. At a minimum how many OTHER WITHDRAW decisions must occur by evening?

e. How much will you earn from a HOLD decision if 2 OTHER depositors withdraw by evening?

f. How much will you earn from a HOLD decision if 3 OTHER depositors withdraw by evening?

g. How much will you earn from a HOLD decision if 4 OTHER depositors withdraw by evening?

h. How much will you earn from a HOLD decision if 5 OTHER depositors withdraw by evening?

i. How much will you earn from a HOLD decision if 6 OTHER depositors withdraw by evening?

3) Suppose that you ARE NOT selected to bank in the morning.

a. What is the minimum number of WITHDRAW decisions that may occur in the morning?

b. Which urn type makes observing the minimum number of morning withdrawals possible?

c. What is the maximum number of WITHDRAW decisions that may occur in the morning?

d. Is it possible to observe the maximum number of morning WITHDRAW decisions with either urn type?

4) Suppose that in the afternoon of a day you observe that one depositor withdrew in the morning

a. At a minimum how many depositors will WITHDRAW in the afternoon?

b. At a maximum, how many depositors may WITHDRAW in the afternoon?

5) Suppose that in the afternoon of a day you observe that 2 depositors withdrew in the morning.

a) Suppose that 2 additional OTHERs withdraw.

- If you HOLD. You will earn

- If you WITHDRAW,

- The maximum amount you can earn from a withdrawal is

- The minimum amount you can earn from a withdrawal is

- The amount you can expect to earn is the average of which entries? 